\title{
A SLIPPERY SLOPE: ON THE ORIGIN, ROLE AND PHYSIOLOGY OF MUCUS
}

Farhan Taherali $^{\text {a }}$, Felipe Varum ${ }^{\mathrm{b}}$, Abdul W. Basit ${ }^{\mathrm{a}^{*}}$

${ }^{a}$ UCL School of Pharmacy, University College London, 29-39 Brunswick Square, London WC1N 1AX

${ }^{\mathrm{b}}$ Tillotts Pharma AG, Baslerstrasse 15, 4310 Rheinfelden, Switzerland 


\begin{abstract}
The mucosa of the gastrointestinal tract, eyes, nose, lungs, cervix and vagina are lined by epithelium interspersed with mucus-secreting goblet cells, all of which contribute to their unique functions. This mucus provides an integral defence to the epithelium against noxious agents and pathogens. However, it can equally act as a barrier to drugs and delivery systems targeting epithelial passive and active transport mechanisms. This review highlights the various mucins expressed at different mucosal surfaces on the human body, and their role in creating a mucoid architecture to protect epithelia with specialized functions. Various factors compromising the barrier properties of mucus have been discussed, with an emphasis on how disease states and microbiota can alter the physical properties of mucus. For instance, Akkermansia muciniphila, a bacterium found in higher levels in the gut of lean individuals induces the production of a thickened gut mucus layer. The aims of this article are to elucidate the different physiological, biochemical and physical properties of bodily mucus, a keen appreciation of which will help circumvent the slippery slope of challenges faced in achieving effective mucosal drug and gene delivery.
\end{abstract}

\title{
KEYWORDS
}

Mucous, mucin glycoprotein, disease, gastrointestinal, respiratory, cervicovaginal, ocular, mucociliary clearance, mucopenetration, mucoadhesion 


\section{CONTENTS}

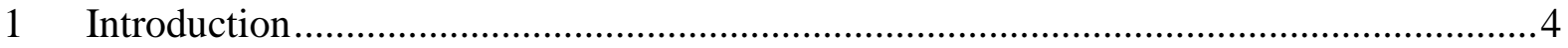

2 Mucosa and mucus: histological, biosynthetic, biochemical and rheological overview ...5

3 The slippery slope: variations in mucus along the gastrointestinal (GI) tract .................12

3.1 Mucosa and mucus of the mouth, esophagus, small and large intestine ...................13

3.2 GI mucus thickness and its relation to turnover...................................................16

3.3 Gastrointestinal mucins and glycosylation in disease ............................................. 19

3.4 The role of gut microbiota in mucus homeostasis.................................................2

3.5 Diffusion across GI mucus and its implication on drug delivery ..............................22

4. Sweeping the dirt away: mucosa and mucus of the respiratory tract...............................23

4.1 Nasal mucociliary clearance and mucins in health and disease.....................................25

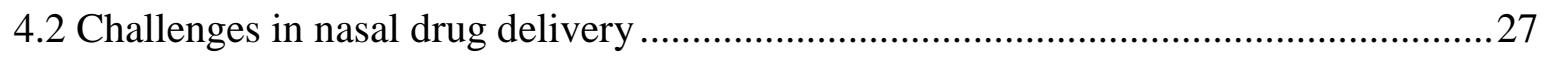

4.3 Lower respiratory mucus and mucins in health and disease .......................................28

5. Is the cervical and vaginal mucus similar? .................................................................. 30

$5.1 \quad$ Mucins of the cervix and vagina ………………….............................................

5.2 Mucin and mucus changes during menstrual cycle and disease ……………...........31

5.2.1 Cervical mucus role in fertility and disease ...................................................... 32

5.3 Diffusion across cervical mucus and means to overcome it for improved drug

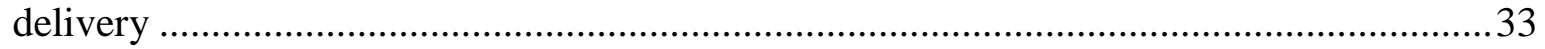

6. Protecting the sclera: the pre-corneal tear film and conjunctival epithelium ...................34

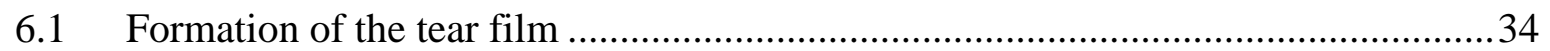

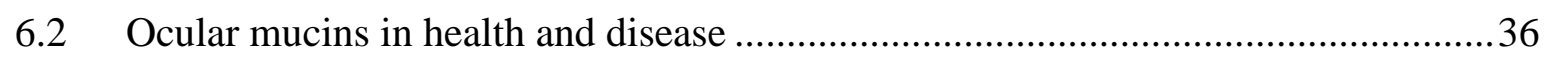

6.3 Implications of ocular mucins on drug delivery ....................................................38

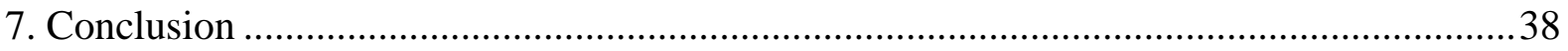

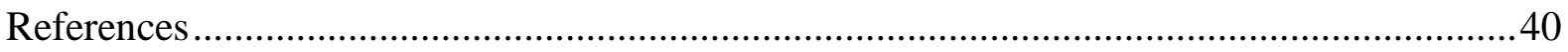

* Corresponding author:

E-mail address: a.basit@ucl.ac.uk (A.W. Basit). 


\section{Introduction}

The mucosal barriers of the human body are integral not only to protect against immunological, chemical and mechanical stresses, but have also increasingly gained prominence for their key role in drug delivery. Mucosa consists of one or more layers of epithelial cells overlying a layer of loose connective tissue, the lamina propria; which is a key part of the mucosal immune system, and followed by the submucosa, consisting of submucosal glands and muscular layers. Some specialized mucosal epithelial cells (such as goblet cells) secrete mucus glycoproteins, which form a layer of viscoelastic mucus on the surface of epithelia. Mucus per se is a semi-permeable network that enables the exchange of nutrients, water, gases, hormones and gametes, whilst being impermeable to most bacteria and pathogens due to its steric obstruction and adhesion properties [1,2]. Cell surface mucins are a prominent feature of the apical glycocalyx of all mucosal epithelia [3].

The properties and functions of mucus secretions are adapted to suit the anatomical location, and can change (as cause or consequence) in disease states where mucus hypersecretion or altered mucin expression is observed [3,4]. Indeed, the differing compositions of the mucosa and mucus of the eye, nose, lower respiratory tract, gastrointestinal tract, cervix and vagina are all individually unique and adapted to perform the functions of these barriers seamlessly, whilst simultaneously protecting the underlying epithelium. For instance, the epithelia of the respiratory tract form a mucociliary escalator [4] that aids the movement and expulsion of trapped inhaled foreign bodies, whereas the transmembrane mucins tethered in the periciliary layer (PCL) form a sieve restricting particles greater than $40 \mathrm{~nm}$ from translocating into the PCL, thereby maintaining sterility $[5,6]$. In turn, a double-layer mucus architecture in the hostile zones of the stomach and colon protect the underlying lining from acid, enzymes (pepsin and proteases) and microbial aggressors [7, 8]. Endogenous hormone secretion from the epithelia of the cervix and vagina also changes the viscoelasticity of cervical mucus in different stages of the menstrual cycle, to either promote or prevent conception [9]. Dietary influences have also been observed to modulate the colonic mucus; low-fibre diets, for instance, have been shown to lead to thinning of mucus owing to associated bacterial colonisation $[10,11]$. This thinning exposes the epithelium to bacterial contact and translocation into the mucosa, eliciting an immunological response and further damage and inflammation, as seen in ulcerative colitis [12]. These properties of mucus in the healthy state, however, make it an excellent guard against immunological as well as chemical and mechanical damage, thereby allowing the mucosa to carry out its normal physiological functions.

While mucus precludes the permeation of drugs, proteins, peptides and nanoparticulate drug delivery systems $[13,14]$, certain capsid viruses have been observed to diffuse through cervicovaginal mucus at rates similar to that in water [15], implying that this barrier cannot restrict surface neutral particles from reaching and infecting the epithelium. Additionally, the mucus pore size and rheology also influence this phenomenon [16]. This property has been exploited towards the design of muco-inert polyethylene glycol coated nanoparticles that are muco-penetrating for cervico-vaginal and ocular delivery $[17,18]$. Overall, this knowledge 
can be used to design drug delivery systems to diffuse 'upstream' against the secretion and shedding of mucus to deliver drugs to epithelia.

Furthermore, mucus secreting epithelia continuously secrete and turnover mucus to create a physiological clearance mechanism. However, this protective mechanism can also cause undesirable drug clearance, a common barrier to drug delivery. As such, in order to deliver the drug payload, and hence achieve the desired drug exposure, prolonged contact of the formulation at the target site is desirable. Mucoadhesive systems have been employed by virtue of their ability to interact with the mucin glycoprotein; whereby mucoadhesive excipients by swelling and interdiffusion of the polymer chains bond with mucin fibers through hydrogen bonding, disulfide bonding, electrostatic and/or hydrophobic interactions. An in-depth review of mucoadhesion as a concept to increase residence time is beyond the scope of this review which focuses on the physiological aspects of mucosa and mucus and therefore the following references [19-23] will provide the reader with greater insight in the area of mucoadhesion.

This article reviews the mucosal histology in relation to the arrangement of goblet cells and submucosal glands. The biosynthesis and release mechanism of mucin from the goblet cells and the physiological and mechanical characteristics of the mucus lining different epithelia are here discussed. Additionally, the functionality of the mucus lining and its dynamic composition are discussed in their role of health and disease.

\section{Mucosa and mucus: histological, biosynthetic, biochemical and rheological overview}

The mucosal epithelium is interspersed with goblet cells which secrete mucus and protect the epithelial cells. If antigenic materials translocate through the epithelium, it triggers an immune response in the underlying lamina propria and submucosa which can comprise the connective tissues of the mucosa $[24,25]$. The immune response is characterized by inflammation and epithelial destruction, exacerbating the damage. Therefore, mucus serves as a tenacious semipermeable barrier allowing only nutrients, gases and certain agents to permeate through it, while trapping noxious agents, bacteria and particles thereby preventing them from reaching the epithelium $[2,26]$.

The goblet (mucus producing) cell is ubiquitous in the mucosa consisting of single columnar cells intercalated in the epithelium. There are two types of mucins; the secreted gel-forming mucins, forming a gel layer over the epithelium and transmembrane mucins which form the 'glycocalyx' at the apical surface of the epithelium. The secreted mucins as described in Table 1 are glycoproteins, made-up of multiple monomers which are joined together to form an oligomer that forms the entangled mesh like structure [27]. Transmembrane (cellassociated) mucins which constitute the glycocalyx, are anchored to the cell surface by a transmembrane SEA domain (sea-urchin sperm protein, enterokinase and agrin) that 
undergoes auto-proteolysis. The SEA domain appears to have evolved to break apart in response to mechanical stress, shedding the mucin without disrupting the membrane [28].

These mucins have high molecular weights (1-40 x $10^{6}$ Daltons) and are comprised of a protein core (800 amino acid residues) around $60-80 \%$ of which is attached to oligosaccharide branches (2-22 sugars in length). The number, length and amino acid sequence of these glycosylated domains differ between mucins [29-31]. The mucin monomer is about $0.2-0.6 \mu \mathrm{m}$ in length with disulphide rich cysteine domains at $\mathrm{N}$ and $\mathrm{C}$ terminal ends. The mucin monomer has tandem repeat units of PTS (proline, threonine and serine), amino acid domains that are highly glycosylated. These includes glycans such as Nacetylgalactosamine (GalNAc) O-linked to threonine and serine and elongated by different monosaccharides including galactose (Gal), $\mathrm{N}$-acetylglucosamine (GlcNAc), fucose (Fuc) and sialic acids by the action of various glycosyltransferases and can also be sulfated. The PTS glycan domains are resistant to proteolysis. Each monomer is separated by 'naked' protein domains about 110 amino acid in length interspersed with cys-rich domains which form intramolecular disulfide bonds and avidly bind lipids which impart the hydrophobicity to the mucin and ultimately to the mucus [32]. The SH groups at the cysteine domains, helps establishing intermolecular disulphide bridges between monomers to form dimers and trimers at the $\mathrm{C}$ and $\mathrm{N}$ terminals, respectively. The sialic acid and sulfate residues are fully ionized at $\mathrm{pH}>2.6$, thereby conferring a negative charge to the mucin molecule at higher $\mathrm{pH}$. Sialylation occurs predominantly in colonic mucins and has been shown to contribute to degradation resistance of mucins to colonic bacteria. An increasing gradient of sialo and sulfomucins has been observed in human, rat, rabbit and pig large intestine; correlating well with the denser bacterial population towards the distal regions [33, 34]. 
Table 1: The secreted and transmembrane mucins at various epithelial surfaces

\begin{tabular}{|c|c|c|c|c|c|c|c|c|c|}
\hline Mucus & & & & & Mucosal surfac & & & & \\
\hline & Mouth & Esophagus & Stomach & Small intestine & Large intestine & Nasal & $\begin{array}{l}\text { Trachea and } \\
\text { bronchi } \\
\text { (pulmonary) }\end{array}$ & $\begin{array}{l}\text { Endocervix } \\
\text { (Cervicovaginal) }\end{array}$ & Ocular \\
\hline Mucus layers & None [34] & None[35] & $\begin{array}{l}\text { Outer, } \\
\text { unattached } \\
\text { layer, inner } \\
\text { attached } \\
\text { layer[34] }\end{array}$ & $\begin{array}{l}\text { Single, unattached } \\
\text { layer[34] }\end{array}$ & $\begin{array}{l}\text { Outer, unattached } \\
\text { layer, inner } \\
\text { attached layer[34] }\end{array}$ & $\begin{array}{l}\text { Outer gel } \\
\text { layer, inner } \\
\text { periciliary } \\
\text { layer [36] }\end{array}$ & $\begin{array}{l}\text { outer gel layer, } \\
\text { inner periciliary } \\
\text { layer[37] }\end{array}$ & $\begin{array}{l}\text { Single, unattached } \\
\text { layer[38] }\end{array}$ & $\begin{array}{l}\text { Secreted } \\
\text { mucins do } \\
\text { not form a } \\
\text { layer }\end{array}$ \\
\hline $\begin{array}{l}\text { Gel forming } \\
\text { mucins: }\end{array}$ & & & & & & & & & \\
\hline Surface/crypt & NF [34] & $\mathrm{NF}$ & $\begin{array}{l}\text { MUC 5AC } \\
{[34]}\end{array}$ & MUC 2[34] & MUC 2[34] & $\begin{array}{l}\text { MUC 5AC } \\
\text { (MUC2)[36] }\end{array}$ & MUC 5AC[37] & $\begin{array}{l}\text { MUC 5AC, } \\
\text { MUC 5B[38] }\end{array}$ & \\
\hline Gland & $\begin{array}{l}\text { MUC 5B } \\
{[34]}\end{array}$ & MUC 2[35] & MUC 6[34] & MUC 6[34] & NF[34] & MUC 5B[36] & MUC 5B[37] & MUC 6[38] & \\
\hline Paneth cells & NA [34] & NA & NA[34] & MUC 2[34] & NA & NA & & & \\
\hline $\begin{array}{l}\text { Transmembra } \\
\text { ne mucins on } \\
\text { epithelial cells }\end{array}$ & $\begin{array}{l}\text { MUC1 } \\
\text { MUC 16[34] }\end{array}$ & - & MUC 1[34] & $\begin{array}{l}\text { MUC 1, MUC 3, } \\
\text { MUC 4, MUC 12, } \\
\text { MUC 13, MUC } \\
\text { 17[34] }\end{array}$ & $\begin{array}{l}\text { MUC 1, MUC 3, } \\
\text { MUC 4, MUC 12, } \\
\text { MUC 13, MUC } \\
\text { 17[34] }\end{array}$ & $\begin{array}{l}\text { MUC1, MUC } \\
4[36]\end{array}$ & $\begin{array}{l}\text { MUC1, MUC 4, } \\
\text { MUC 16 [37] }\end{array}$ & $\begin{array}{l}\text { MUC1, MUC4, } \\
\text { MUC } 16 \text { [38] }\end{array}$ & $\begin{array}{l}\text { MUC1, } \\
\text { MUC4, } \\
\text { MUC13, } \\
\text { MUC15 } \\
\text { MUC16, } \\
\text { MUC17, } \\
\text { MUC20[39] }\end{array}$ \\
\hline $\begin{array}{l}\text { Secreted } \\
\text { mucins }\end{array}$ & MUC 7[34] & $\mathrm{NF}[35]$ & NF[34] & $\mathrm{NF}[34]$ & $\mathrm{NF}[34]$ & MUC 7[36] & & & $\begin{array}{l}\text { MUC5AC, } \\
\text { MUC } 7\end{array}$ \\
\hline
\end{tabular}

Abbreviations: NA, not applicable; NF, not found 
Besides mucin, which is the main component responsible for the structure and functions of mucus, a number of other components are present within the mucus layer. Mucus is composed of water (95\%), mucin (glycoproteins which provide the gelling and viscoelastic properties), lipids, proteins, sloughed epithelial cells, DNA and inorganic salts. Amongst the main important proteins secreted into the mucus layer are secretory immunoglobulin A (SIgA), lysozyme, lactoferrin, FCGBP and trefoil peptides [40]. SIgA is secreted by the epithelial cells into the mucus layer and serves to inhibit epithelial attachment of antigens capable of eliciting an immune response. FCGBP is covalently attached to mucins and its exact role is not known. It is probably responsible for the binding of IgG allowing its diffusion through the mucus to translocate antigens to be presented to the antigen-presenting cells (APC) for immune protection [41]. Trefoil peptides are co-secreted along with mucus by mucus-producing cells in the gastrointestinal tract and have been involved in cell migration from the crypts and cell repair after damage, a process known as 'epithelial restitution' [42].

As seen in figure 1, the polymeric mucin assembly starts in the endoplasmic reticulum (ER), where the non-O-glycosylated mucin monomer forms dimers [41] via disulphide bonds formed between $\mathrm{C}$ - terminals. In the Golgi apparatus, mucin dimers are O-glycosylated and then multimerized by disulphide bonds formed between $\mathrm{N}$-terminal domains. In the case of MUC5B, multimers form between dimers of dimers [43] whereas multimers of MUC2 form trimers of dimers [44]. The mucin multimers are then packed in an ordered state within the secretory granules in the presence of high concentration of $\mathrm{Ca}^{2+}$ and $\mathrm{H}^{+}$. The $\mathrm{H}^{+}$neutralizes the otherwise negatively charged sialic acids and the $\mathrm{Ca}^{2+}$ cross-links the remaining negatively charged glycans (sulphate groups) [45]. For instance, the MUC2 monomeric building block has a mass of approx. 2.5MDa when fully glycosylated and is polymerized by $\mathrm{C}$-terminal dimerization and $\mathrm{N}$-terminal trimerization, resulting in the formation of enormous net-like polymeric sheets [46, 47]. 


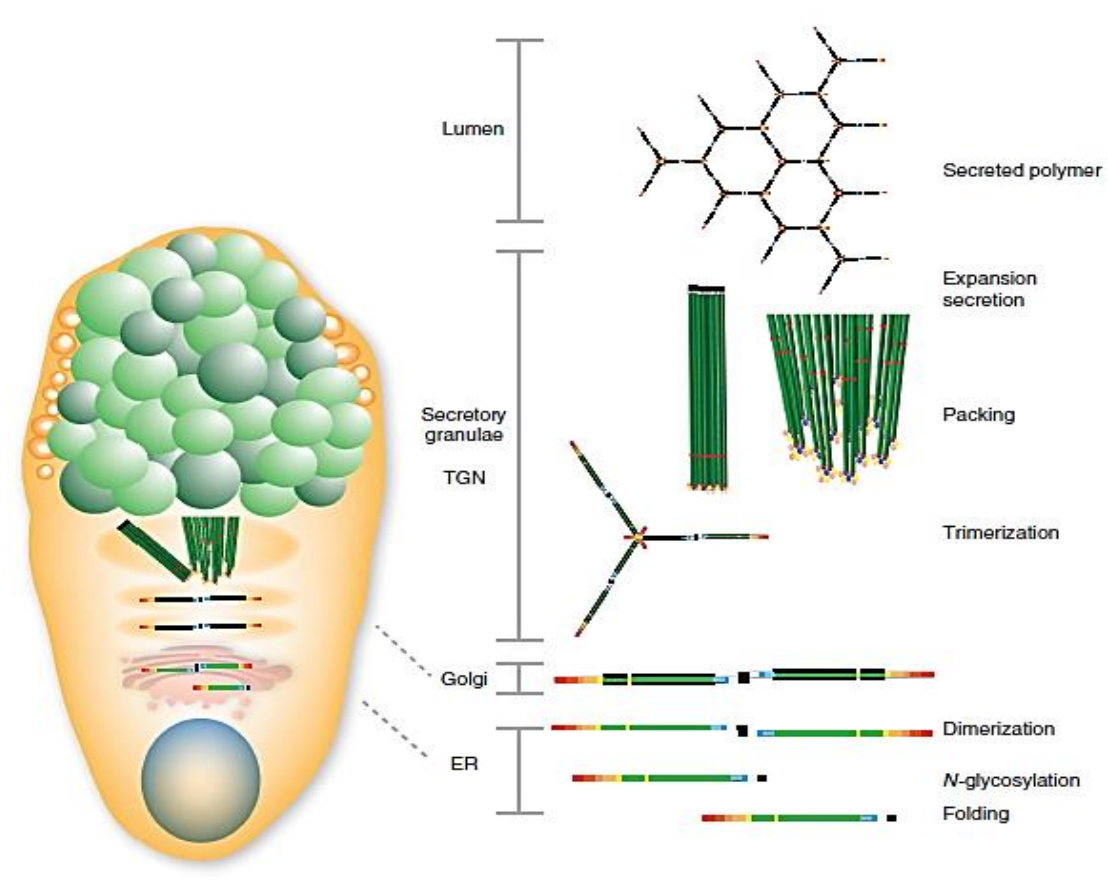

Figure 1: Assembly of the MUC2 mucin in the goblet cell. ER, endoplasmic reticulum; TGN, trans-Golgi network. Reprinted with permission from [46].

When mechanically or chemically stimulated, goblet cells respond promptly whereby most of the mucus granulae in the goblet cell theca are fused and released, emptying the whole cell interior leaving a thin cell which is sometimes mistaken for the reduced goblet cell count in inflammatory bowel disease $[46,48]$. When the mucin is secreted, $\mathrm{Ca}^{2+}$ and $\mathrm{H}^{+}$diffuse away and the granule swells explosively expanding about 500-fold in volume in $50 \mathrm{~ms}$ [49]. In the small intestine, for example, mucus expansion upon secretion is facilitated by increasing $\mathrm{pH}$ and sequestration of $\mathrm{Ca}^{2+}$ through release of bicarbonate ions $\left(\mathrm{HCO}_{3}^{-}\right)$by cystic fibrosis transmembrane conductance regulator (CFTR) in the epithelial cell [44], as depicted in Figure 2. The mucin sheets which are attached to the epithelium are then released by endogenous protease, Meprin $\beta$. Meprin $\beta$ is anchored in the enterocyte apical membrane and cannot access the mucin goblet cell anchor from this position. To interact with MUC2 it needs first to be released by extracellular cleavage, allowing it to diffuse into the mucus. The release of anchored Meprin $\beta$ is controlled and triggered by exposure to bacteria as evidenced by germ-free mice which have the small intestinal mucus attached to the epithelia but when recombinant Meprin $\beta$ was added, the mucus layer detached [50]. 


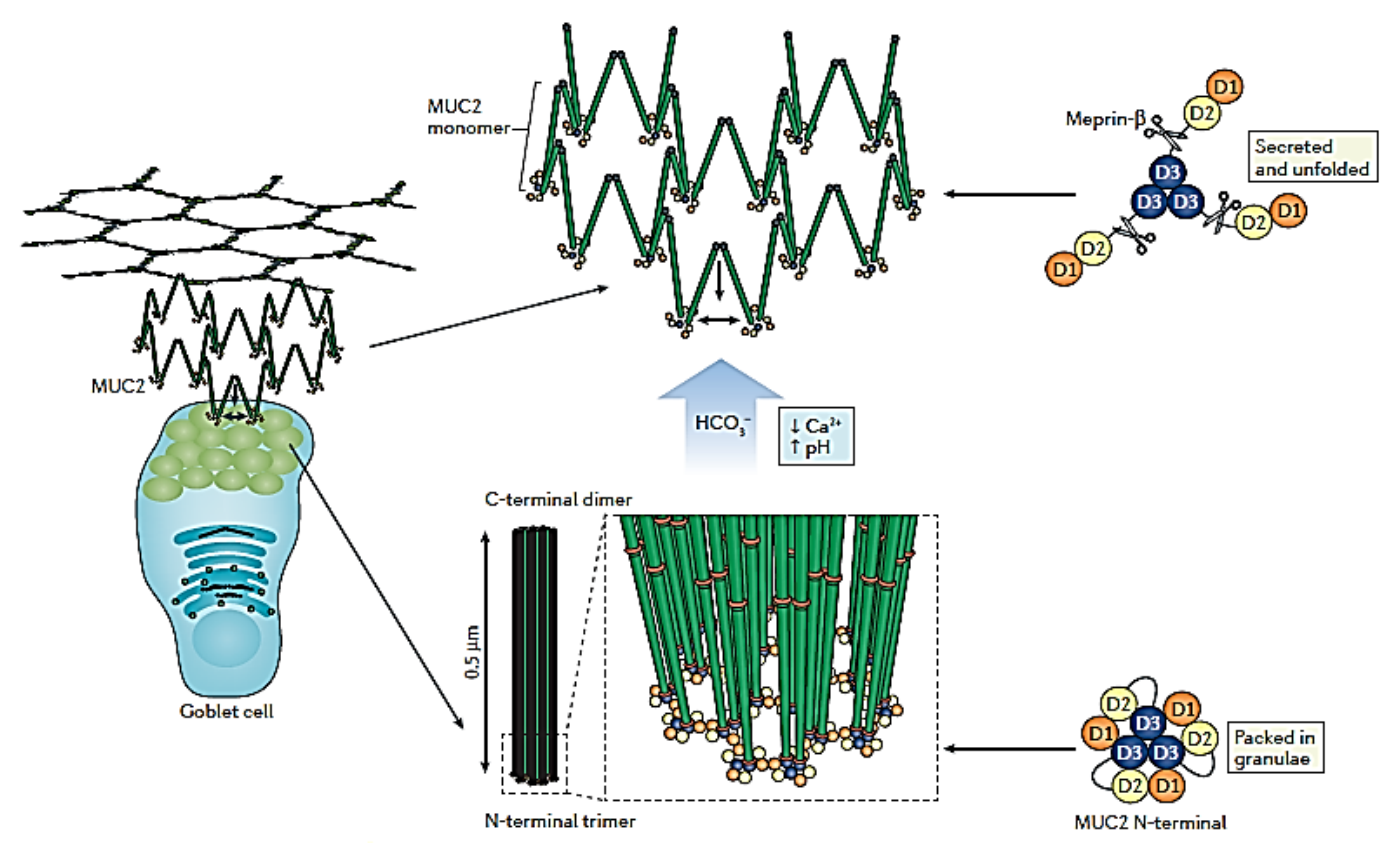

Figure 2: The mucin-release mechanism in the small intestine. Reprinted with permission from [51].

The complex interplay of glycans, hydrophobicity, lipids, disulphide bonding and molecular weight of the mucin oligomer, when released and coming in contact with water, gives mucus its viscoelastic gel like properties, since mucins bind and retain significant amounts of fluid. At the macroscopic (bulk level) mucus is a thixotropic gel; under low shear it acts like an elastic solid and under high shear as a viscous liquid. Mucus viscoelasticity is of critical importance for the protective and lubricant functions of mucus [16]. The bound lipids may also form numerous low-affinity bonds between overlapping mucins thereby increasing the viscoelasticity of the mucus gel. Delipidation of mucins by lyso-lecithin and treatment with $\mathrm{N}$-acetyl cysteine which breaks $\mathrm{S}-\mathrm{S}$ bonds significantly decreased mucus viscoelasticity whereas exposing mucin to $\mathrm{pH}<4$ greatly increases the hydrophobicity by exposing hydrophobic domains within the protein core, causing the mucin bundles to aggregate and increasing its viscoelasticity $[52,53]$.

When the mucus layer undergoes shearing action, as seen by the blinking of eyes, copulation, coughing and peristalsis, a lubricating slippage plane of mucus forms between the two surfaces while keeping the gel layers adherent to the surface intact (i.e entangled and unstirred) thereby preventing the diffusion of nanoparticles [16]. The viscosity of human mucus is $10^{4}-10^{6}$ times that of water and is greatly reduced when subjected to high shear. This macrorheological property of mucus, has been used as reference when studying the barrier properties of mucus at various mucosal surfaces and has helped to select animal models closest to humans [16]. The pig is a popular model for characterizing gastrointestinal tract mucus; having both the adherent layer resistant to shear and loosely bound layer that is shear complaint and similar in mucin molecular weight [54]. While rat mucus is 10 -fold less 
viscoelastic than that of human, it is commonly used in studying nasal, lung and gastrointestinal mucus owing to its similarity in slope log viscosity vs. log shear rate $[16,55]$.

The duodenal mucus is less viscoelastic than gastric and colonic and this is reflected by the fact that it traps and propels the particles by its property of viscidity whereas the adherent layer of colonic mucus acts as a size exclusion sieve not allowing bacteria $>0.5 \mu \mathrm{m}$ to come in contact with the epithelia [12]. The optimal viscoelasticity of the gel layer on the nasal and pulmonary mucosa also allows for sufficient contact between the cilia and the mucus gel; the shear force exerted by the cilia reduces the mucus viscoelasticity and facilitates transport of the mucus towards the mucopharynx for ingestion in the GI tract [56]. The ovulatory mucus owing to its lower viscoelasticity, promotes the motility of sperm whereas the non-ovulatory mucus hinders it $[57,58]$. 


\section{The slippery slope: variations in mucus along the gastrointestinal (GI) tract}

The gastrointestinal wall is composed of four different layers: the mucosa, the submucosa, the muscularis and the serosa. The mucosa is further subdivided into three main layers: the muscularis mucosa, lamina propria and the epithelium. The mucus largely establishes the first barrier for absorption through the gastrointestinal tract. Figure 3 below illustrates the mucus architecture along the gastrointestinal tract of humans.

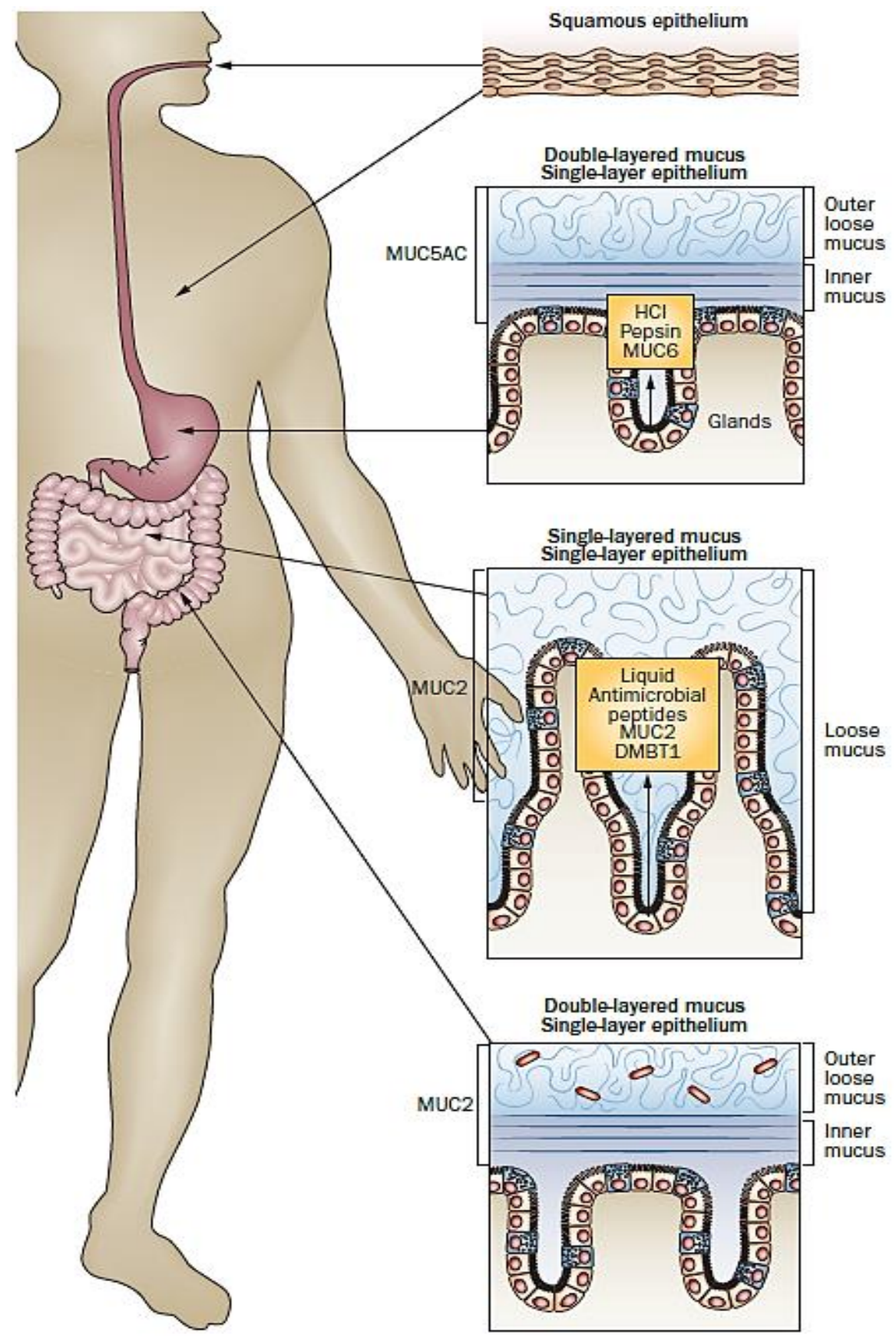

Figure 3: The organization of epithelium and mucus in the gastrointestinal tract. Reprinted with permission from [59]. 


\subsection{Mucosa and mucus of the mouth, esophagus, small and large intestine}

The buccal mucosa (the inner lining of the cheek) and sublingual mucosa comprises the epithelium, lamina propria, submucosa and muscularis mucosa. This mucosa is lined by nonkeratinized stratified squamous epithelium, which consists of 40-50 cell layers (500-600 $\mu \mathrm{m}$ thickness), which migrate from the basal layer to the superficial layer, and protect the underlying tissue against fluid loss and entry of potentially harmful environmental agents [60, 61]. The intercellular spaces of the epithelia have cytokeratin protein [62], small amounts of ceramides and neutral but polar lipids, mainly cholesterol sulfate and glucosylceramides [63, 64].

Saliva is secreted by three major salivary glands (parotid, submaxillary and sublingual). Saliva mainly consists of water (95-99\% per weight), enzymes, inorganic salts, lipids, and mucins. In the mouth, the salivary glands produce MUC5B and MUC7, which lubricate ingested food for passage through the esophagus forming a salivary film of average thickness between 70 and $100 \mu \mathrm{m}$ on the buccal epithelium [59, 65, 66]. The salivary mucin, MUC7 which is not oligomerized, is not thought to contribute towards mucus like properties. However, it has inherent direct candidacidal activity [67, 68]. MUC5B's complex structure allows it to interact with an array of different salivary proteins and microbes to maintain a healthy oral cavity. Streptococcus mutans is a cariogenic bacteria that attaches to the tooth surface and damages the enamel through release of acidic metabolites from sucrose utilization. MUC5B binds to $S$. mutans and decreases surface attachment and biofilm formation thereby playing an anti-cariogenic role [69].

The esophageal mucosa has a surface area of about $235 \mathrm{~cm}^{2}$ in man and acts as a conduit for the passage of food to the stomach [70]. The $\mathrm{pH}$ within the esophagus is similar to that of the saliva pH 6-7 and is maintained by the bicarbonate secretion from the esophageal submucosal glands (SMGs). SMGs are present in the submucosa of human, pig and dog which have a non-keratinized stratified squamous epithelium and are absent in rodents (keratinized stratified squamous epithelium) [71, 72]. The SMGs also secrete a mucin like substance which is primarily neutral in nature and hence loosely bound in comparison to acidic mucin which has a tendency to form an adherent layer as seen in the large intestine. The SMGs may be responsible for the luminal acid clearance in cases of gastroesophageal reflux. The unstirred water layer resident on the esophageal epithelium is estimated to be $30 \mu \mathrm{m}$ thick and does not account for mucus like substance; which is secreted in quantities so low in comparison to stomach that it cannot afford protection to the underlying epithelial cells [72, 73].

The gastric mucosa consisting of a single layer of columnar epithelial cells, is resilient to the effects of proteolytic enzyme pepsin and hydrochloric acid; owing to the impervious nature of the double layer mucus architecture. The surface epithelial cells secrete bicarbonate and 
foveolar cells in the neck of the gastric pits secrete MUC5AC, creating a pH gradient from the acidic lumen $(\mathrm{pH} \mathrm{1-2)}$ to neutral $\mathrm{pH}$ at the cell surface $[74,75]$ whereas MUC6 is produced in the glands and is secreted together with hydrochloric acid and pepsin [76]. The estimated surface area of the human gastric mucosa is $500 \mathrm{~cm}^{2}$ and is lined by the epithelial (mucus) and glandular cells [70].

Interestingly, these gland secretions are able to cross the surface of the inner mucus layer through what looks like temporary channels. Immunohistochemical studies have shown that the two layers, MUC5AC and MUC6, are arranged in alternating layers, whereby MUC5AC appears adjacent to the surface epithelium and with MUC6 acting as a barrier towards the back-diffusion of hydrochloric acid and pepsin. The higher the concentration of mucin, the greater the viscoelasticity and thickness of the mucus layer, hindering the back-diffusion of hydrogen ions. This thick and viscoelastic mucus layer has a higher capacity to retain bicarbonate released into the mucus layer from the mucosa. Additionally, the acidic $\mathrm{pH}$ $(\mathrm{pH}<2)$ keeps the adherent mucus in gel state probably owing to aggregation of mucin fibers [60-62]. The gastric mucin together with the bicarbonate buffer and high concentration (25\% dry weight) of hydrophobic phospholipids is responsible for the first line of gastric mucosal defence that prevents or slows down $\mathrm{H}^{+}$back diffusion and stomach self-digestion [8]. Cosecreted trefoil peptides also play a role in maintaining epithelial health by promoting epithelial restitution and increasing mucus viscoelasticity (TFF 1 and 3). TFF2 increases the viscosity of the mucosal layer and stabilizes the gel network [77].

Ulcerogenic substances such as aspirin and NSAIDs, by inhibition of prostaglandin D2, disrupt the mucus gel and the phospholipid layer, promoting mucosal injury. Furthermore, Helicobacter pylori triggers proteolysis and lipolysis of the mucin-lipid network, decreasing its viscosity and impairing the defense mechanism establishing a strong causal relationship to gastric ulcers [78, 79]. Idiopathic peptic ulcers are thought to be caused by aberrant mucin secretion, age, smoking or acid hypersecretion [80]. Certain bacterial lipopolysaccharides (LPS) for e.g Pseudomonas aeruginosa and Hemophilus influenza upregulates the expression of MUC5AC but reduces its glycosylation and sulfation thereby compromising its protective nature [81]. While the main role of proton pump inhibitors (PPIs) is to reduce gastric acid secretion by inhibiting the $\mathrm{H}^{+}-\mathrm{K}^{+}$ATPase pump in the parietal cells, PPIs like leminoprazole [82] and rabeprazole [83] have been found to increase secretion and viscosity of gastric mucus thereby further enhancing its barrier forming properties.

In the intestinal tract, the transmembrane mucins MUC3, MUC4, MUC12, MUC13 and MUC17 are constitutively expressed, whereas MUC1 and MUC16 are upregulated in response to infection and cancer [51]. The transmembrane mucins play a role in cell signalling and MUC16, the longest mucin of about $700 \mathrm{~nm}$ in length, probably senses the extracellular environment and sends signals to the immune system. Through this mechanism, also thought to promote epithelial barrier integrity MUC17 executes a defensive role especially towards pathogenic Escherichia coli $[84,85]$. 
MUC2 is the primary mucin-forming mucus of both small and large intestine, however, the biochemistry in the formation of the loose mucus is totally different between the two. The loosely bound nature of the small intestinal mucus is dependent on the CFTR whereas that of the colon relies on the endogenous proteases converting the inner adherent mucus into loosely bound mucus [50, 86]. In a study by Johansson and co-workers [7], it was established that there was a difference in MUC2 concentration between the firm and loose layers with a lower proportion in the latter. The reduced MUC2 in the loose layer is due to proteolytic cleavages as confirmed by applying protease inhibitors mixture inhibiting serine and cysteine proteases to the firm layer in vivo. A decreased replenishing rate of loose mucus was observed but firm mucus was not affected and there was an increased MUC2 concentration in the loose layer. This argument is further strengthened by the fact that the presence of a loose mucus layer in colon of germ free mice suggests that the formation of the loose mucus is due to endogenous proteases. Additionally, when a firm mucus pellet was treated with trypsin (a serine protease) of pancreatic origin for 3 hours, it resulted in a volume expansion of the pellet.

The small intestinal mucus layer is relatively impenetrable as it traps and wraps pathogens moving them distally to the colon with the help of the migrating motor complex (MMC), which is a contractile activity of the muscles stimulated by the nerves. This ability to trap bacteria comes from a property of mucus known as 'viscidity' [2]. This is further enhanced by the ability of mucus layer to limit the diffusion of bacteria while simultaneously generating a gradient of antibacterial proteins and peptides secreted by the Paneth cells [87, 88]. The Paneth cells at the bottom of the crypt not only secrete antibacterial peptides and lysozyme, but also scaffolding proteins such as MUC2. Combined secretion of mucins and fluid from the crypts help to ensure that this compartment remains relatively depleted of bacteria [89].

The adherent firm layer in the large intestine is free from bacteria acting as a size exclusion filter, not allowing bacteria of diameter less than $0.5 \mu \mathrm{m}$ to permeate through and reach the epithelium. The bacterial count in the small intestine is $10^{2}-10^{4} \mathrm{cfu} / \mathrm{ml}$ and increases distally towards the ileum thus explaining the loosely bound nature of small intestinal mucus which is relatively sterile in comparison to the colon $[90,91]$. The colonic mucus harbors a large biodiversity of microbiota $\left(10^{12}-10^{14} \mathrm{cfu} / \mathrm{g}\right)$ which have an important role in metabolism. At $50 \mu \mathrm{m}$ (mouse) or $200 \mu \mathrm{m}$ (human) distance from the underlying epithelium, endogenous protease activities convert the inner mucus layer into the outer non-attached mucus that is slowly expanded 2-3-fold in volume [7, 12].

Germ-free animals have a penetrable (defective) colonic inner mucus as is also the case for animals lacking the NHE3 (sodium-hydrogen exchanger 3) ion transporter or cytokine interleukin (IL)-10 [12, 91]. The mucus probably becomes penetrable due to an ionic imbalance or digestion by proteolytic enzymes released by the immune cells e.g neutrophil elastase. The bacteria in such animals are in direct contact with the epithelium eliciting an inflammation as seen in MUC 2 deficient mice. In these models inflammation occurs almost spontaneously as opposed to that seen in DSS (dextran sodium sulphate) models of colitis 
where rodents are given 2-5\% DSS over a period of 5 days. Bacteria are seen in contact with the epithelium within the first 12 hours but inflammation ensues later being different from the models discussed earlier. The mechanism of DSS colitis differs in that, complexes of DSS and fatty acids are formed in mucus, which translocate into the epithelial cell damaging it and eliciting colitis. The penetrable mucus layer, as also observed in patients suffering from ulcerative colitis, allows a greater than usual number of bacteria to come in contact with the epithelia thus overwhelming the immune system and initiating the recruitment of inflammatory cells and cytokines [92].

\subsection{GI mucus thickness and its relation to turnover}

The thickness of the gastrointestinal mucus layer is a consequence of the balance between its secretion rate and its erosion through bacterial enzymatic digestion or mechanical shear. The resistance to proteolytic activity has been found only in the glycosylated regions [93]. In vitro measurements with a method not employing organic solvents/fixatives does not cause shrinkage and dehydration of the mucus layer as measured in rat gastric mucus thickness approximately $144 \pm 52 \mu \mathrm{m}$ which is 5 -fold greater than $39 \pm 14 \mu \mathrm{m}$ measured when using fixatives [94]. In vitro studies have shown a thicker gastric mucus relative to caecum and colon whilst in vivo studies using micropipette and intravital microscope on the contrary have shown the highest mucus thickness in the colon $830 \pm 110 \mu \mathrm{m}$ relative to other regions in the GIT [95-97]. Large differences in the mucus thickness have been seen when using in vitro vs in vivo methods probably owing to the fact that the loose mucus layer gets washed away in the process of preparing the histological specimen. In the human colon, the mucus thickness has been reported to increase from proximal to the distal regions in the rectum where the bacterial load is greatest thus requiring greatest protection [60]. These reported values are presented in Table 2 where interspecies comparisons can also be made using the same histological method for rat, rabbit, pig and human.

The mucus turnover along the gastrointestinal tract of humans has been reported between 24$48 \mathrm{~h}$ [20] and correlates with the colonic transit time in humans, measured between 26-50 hours [98]. Mucin glycans in mice have been labelled by $\mathrm{N}$ - azidoacetyl galactosamine (GalNAz). The investigation of the colon demonstrated that crypt goblet cells were labelled very slowly whereas the goblet cells on the surface have faster mucin biosynthesis and secretion. Goblet cells at the luminal surface epithelium had fastest biosynthesis of MUC2 and secreted material 3 hours after labelling. In 3 hours, the labelled mucus was also observed in the outer side and this mucus was replaced by evenly stained mucus at 4 hours which demonstrates that the inner mucus turnover in the distal colon is 1 hour. Mucin secretion from the crypt goblet cells at the top of the crypt was first observed after 6 hours and was frequently after 8 hours. Crypt goblet cells normally release mucus when stimulated whereas luminal surface goblet cells secrete mucus at a basal rate [29, 46]. 
Table 2: Physiological parameters in different regions of the gastrointestinal tract in humans and animals

\begin{tabular}{lllll}
\hline Gastrointestinal & Mouse & Rabbit & Pig & \\
Parameter & & & \\
\hline
\end{tabular}

\section{Stomach}

Mucus thickness $(\mu \mathrm{m})$

Fundus

Body

Antrum

antrum

pH of mucus layer

Mucus turnover

\section{Small intestine}

Mucus thickness $(\mu \mathrm{m})$

$\begin{array}{lllll}\text { Duodenum } & 200-300^{\mathrm{c}} & 30.6(8.8)^{\mathrm{a}} & 73.3(42.6)^{\mathrm{a}} & 25.6(12.2)^{\mathrm{a}} \\ \text { Jejunum } & & 38.5(16.4)^{\mathrm{a}} & 94.6(67.9)^{\mathrm{a}} & 35.3(17.8)^{\mathrm{a}} \\ \text { Ileum } & & 34.1(14.9)^{\mathrm{a}} & 147.8(115.6)^{\mathrm{a}} & 53.8(22.1)^{\mathrm{a}}\end{array}$

pH of mucus layer

Mucus turnover

$$
\text { Ileum }
$$

$\begin{array}{lll}31.3(11.4)^{\mathrm{a}} & 155.1(85.8)^{\mathrm{a}} & 190.7(80.7)^{\mathrm{a}} \\ 57.9(34.8)^{\mathrm{a}} & 124.5(68.8)^{\mathrm{a}} & 213.9(87.9)^{\mathrm{a}} \\ 69.4(24.8)^{\mathrm{a}} & 277.6(129.4)^{\mathrm{a}} & 222.2(112.2) \\ & & \\ & \\ & & \\ & & \\ 30.6(8.8)^{\mathrm{a}} & 73.3(42.6)^{\mathrm{a}} & 25.6(12.2)^{\mathrm{a}} \\ 38.5(16.4)^{\mathrm{a}} & 94.6(67.9)^{\mathrm{a}} & 35.3(17.8)^{\mathrm{a}} \\ 34.1(14.9)^{\mathrm{a}} & 147.8(115.6)^{\mathrm{a}} & 53.8(22.1)^{\mathrm{a}}\end{array}$

$425^{\mathrm{d}}$

$144(52)^{b}$

$100^{c}$

${ }^{\mathrm{c}}$

$576^{\mathrm{d}}$

$6.4(0.24)^{e}$

$24-48 h^{g}$

$15.5^{b}$

$5.5-7.5^{f}$

$24-48 \mathrm{~h}^{\mathrm{g}}$

Large Intestine (Colon) 
Mucus thickness $(\mu \mathrm{m})$

Caecum

Ascending

$49.6(31.5)^{\mathrm{a}}$

$65.2(39.8)^{\mathrm{a}}$

$134.4(88.4)^{\mathrm{a}}$

$37.2(16.1)^{\mathrm{a}}$

$36.7^{b}$

Transverse

$150^{\mathrm{c}}$

$265.1(125.6)^{\mathrm{a}}$

$68.1(36.5)^{\mathrm{a}}$

$39.1^{\mathrm{b}}$

Descending

$48.4(30)^{\mathrm{a}}$

$63.2(41.2)^{\mathrm{a}}$

$83.6(36.2)^{\mathrm{a}}$

$76.3(56.7)^{\mathrm{a}}$

$57.5^{\mathrm{b}}$

$69.6^{\mathrm{b}}$

Rectum

$111.5(99.6)^{\mathrm{a}} \quad 58.8(27.9)^{\mathrm{a}}$

$101.5^{\mathrm{b}}$

pH of mucus layer

$6.3-6.8^{f}$

Mucus turnover

$1 \mathrm{~h}$

$24-48 \mathrm{~h}^{\mathrm{g}}$
$\mathrm{a}-[96]$
$\mathrm{b}-[19]$
c - [7]
d - [99]
$\mathrm{e}-$ [78]
$\mathrm{f}-[100]$
$\mathrm{g}-[29,101]$ 


\subsection{Gastrointestinal mucins and glycosylation in disease}

The gastric mucus layer in gastric ulcer patients is composed of lower molecular weight mucin (due to proteolysis), which suggests a weaker gel structure and lower efficiency in protecting the underlying epithelium from the harsh conditions of the lumen [102]. The inner layer of the gastric mucus is made up of neutral mucins MUC5AC which have a high viscoelasticity owing to the acidic ( $\mathrm{pH}$ 1-2) luminal environment, thereby preventing the diffusion of pepsin and Helicobacter pylori. However, H. pylori releases urease which neutralizes the stomach acid. Urease disrupts mucin, allowing $H$. pylori to diffuse through it $[78,79]$. In response to infections with $H$. pylori, the viscoelasticity of gastric mucus later increases [103], suggesting that thicker mucus may help preventing infection by motile pathogens.

Pro-inflammatory cytokines such as TNF- $\alpha$ and IL-6, via regulating the glycosyltransferase genes, have been shown to modify the glycosylation pattern of glycoproteins in acute and chronic inflammation [104]. Cytokines in inflammatory bowel disease (IBD) released as a result of acute or chronic inflammation, induce changes in mucin O-glycosylation. Crohn's disease (CD) and ulcerative colitis (UC), two chronic forms of IBD are characterized by chronic inflammation of parts of the gastrointestinal tract resulting from a dysregulated balance between pro inflammatory (TNF- $\alpha$, IL-1 $\beta$, IL-8 and IL-7) and immunoregulatory cytokines (IL-10). Changes in mucin expression, structure and/or glycosylation are likely to influence the protection of the colonic mucosa $[105,106]$. In this connection, several changes have been observed concerning mucins and the mucus layer in UC: the mucus gel layer is thinner than normal $[95,107]$ and goblet cells responsible for the synthesis of secreted mucins such as MUC2 are reduced in number [108].

Alterations in O-glycosylation of mucins especially sialylation and sulfation have been reported in UC. Histological analysis in samples from ulcerative colitis patients have shown an increase in sialic acid residues with depletion of $\mathrm{O}$-acetylation and reduction of sulfate residues, which has been linked to disease severity [109]. Pro inflammatory (TNF- $\alpha$, IL-1 $\beta$, IL-8) cytokines are known modulators of mucin glycosylation [110]. Mass spectroscopy studies have shown that patients with active UC exhibit alterations in MUC2 glycosylation, characterized by an increase in small glycans and lower amounts of larger glycans [111]. The glycosylation modifications have been correlated to result from inflammation rather than genetic defects [112,].

The use of animal models allowed to understand which extent O-glycosylation contributes to development of UC and colorectal cancer. For instance, core-1 glycan deficient mice developed spontaneous colitis in the distal colon and similar to human UC [112]. More severe and spontaneous proximal and distal chronic colitis was observed in core- 1 and core- 3 O-glycan deficient mice [113]. Studying mucins from these mutant mice showed that core 1 
and core 3 derived O-glycans are both necessary to maintain the colonic mucus barrier and protect against colitis.

The viscoelastic property of mucus is key to its effectiveness as a semi-permeable barrier. However, changes in viscoelastic properties can trigger disease or be a consequence of other pathophysiological changes. Mucus can immobilize Escherichia coli, a pathogenic bacteria, which can come into contact with small intestinal epithelia and trigger a proinflammatory response leading to inflammatory bowel disease [114]. Also large parasites, such as Entamoeba histolytica, can proteolitically disrupt MUC2, allowing penetration through the inner mucus by altering viscosity and invade the underlying epithelium [115]. Cathelicidins are antimicrobial peptides released by colonic epithelial cells and protect against Entamoeba histolytica and DSS-induced colitis. They are secreted in the presence of MUC2 and butyrate, a product of bacterial fermentation in the colon but not in MUC2 deficient mice. Therefore intact mucus barrier is essential for expression and secretion of cathelicidin related antimicrobial peptides which only regulates the proliferation and elimination of E. histolytica in the presence of MUC2 [110].

The CFTR channel preferentially secretes bicarbonate and chloride while the adenosine system regulates mucus hydration by inhibiting sodium reabsorption and collectively plays a key role in protecting the small intestine from bacterial invasion. [59]. This function of CFTR can be explained by the disease cystic fibrosis (CF) where there is a non-functional CFTR channel. This disease affects all organs producing mucus with recurrent lung infections being the dominant course. However, it has small intestinal effects; $10 \%$ newborns with meconium ileus at birth and some adults with distal intestinal obstruction syndrome (DIOS). Furthermore, in mice with $\mathrm{CF}$, the mucus was found to be attached to the epithelium and impenetrable but was normalized by exposing it to about $100 \mathrm{mM}$ bicarbonate $[50,87,116]$. Thus, the altered mucus in CF mice was attributed to a lack of bicarbonate owing to the dysfunctional CFTR channel.

\subsection{The role of gut microbiota in mucus homeostasis}

The GI tract is heavily colonized by bacteria and their composition varies longitudinally along the GI tract but also transversally from the mucosa to the lumen [11]. The gut microbiota are believed to derive their energy requirements from the consumption of carbohydrates, proteins and dietary fibres [117]. Apart from these, an alternative energy source for the microbiota is the glycoprotein-rich mucus layer [59]. Food is known to alter the GI milieu and impact drug bioavailability [118]. It may have a mucus sparing effect and impact bioavailability of drugs hindered by mucus. In the event of excessive mucus degradation, the bacteria can easily reach epithelium leading to an inflammatory response and epithelial destruction as seen in ulcerative colitis [12]. 
Mucin-degrading bacteria were considered in a first instance as pathogens [119] but it is now accepted that mucin degradation is part of a normal mucus turnover process starting a few months after birth [11]. Certain bacteria such as Bacteroidetes (e.g Bacteroides thetaiotaomicron), Ruminococcus (Ruminococcustorques and Ruminococcusgnavus), Actinobacteria (Bifidobacterium bifidum, Bifidobacetrium breve and Bifidobacterium longum) and Verrucomicrobia (Akkermansia muciniphila) have been shown to degrade glycosaminoglycans [120-122]. The breakdown of oligosaccharides is used by other bacteria to proliferate while promoting the formation of SCFAs (short chain fatty acids) which are beneficial to the health and metabolic machinery of gut epithelial cells [10]. However, this can also promote the movement of pathogenic bacteria through normally impervious inner mucus layer and elicit an inflammatory reaction.

Recently, Akkermansia muciniphila has been identified as mucin-degrading bacteria that resides in the mucus layer and it is the dominant bacterium that abundantly colonizes this nutrient-rich environment [123]. A. muciniphila may represent 3-5\% of the microbial community in healthy subjects, and its abundance inversely correlates with body weight and type 1 diabetes in mice and humans [124, 125]. A. muciniphila does not grow on oligofructose-enriched media (in vitro), which suggests that complex cross-feeding interactions are involved in the gut where mucus and prebiotics are both present. However, it has been previously shown in rats that oligofructose feeding increases the number of goblet cells and mucus layer thickness [126]. A. muciniphila degrades human mucus [123] and it has yet to be elucidated whether the mucus glycans in combination with prebiotics provide for an energy source for this bacteria. In the absence of prebiotics, this bacterium can forage on mucin glycans, compromising the protective barrier.[122].

This hypothesis can be further strengthened by the findings of Desai et al., [127] represented by figure 4 where it was shown that a fibre rich diet consisting of plant fibres as opposed to soluble fibres (prebiotics) are needed to prevent the microbes of the gut from feeding on the mucus layer. Mice fed a fibre rich diet had intact mucus layers, separating the commensals and pathogens from the epithelium, whereas fibre deprived mice had a high proportion of mucus degrading bacteria and the pathogenic bacteria in contact with the epithelium. Furthermore, it was observed that commensal/good bacteria are not the only ones responsible for preventing colonization by pathogens such as Citrobacter rodentium. A diet rich in fibre provides the necessary energetic resources preventing this pathogen from translocating through the epithelium. 


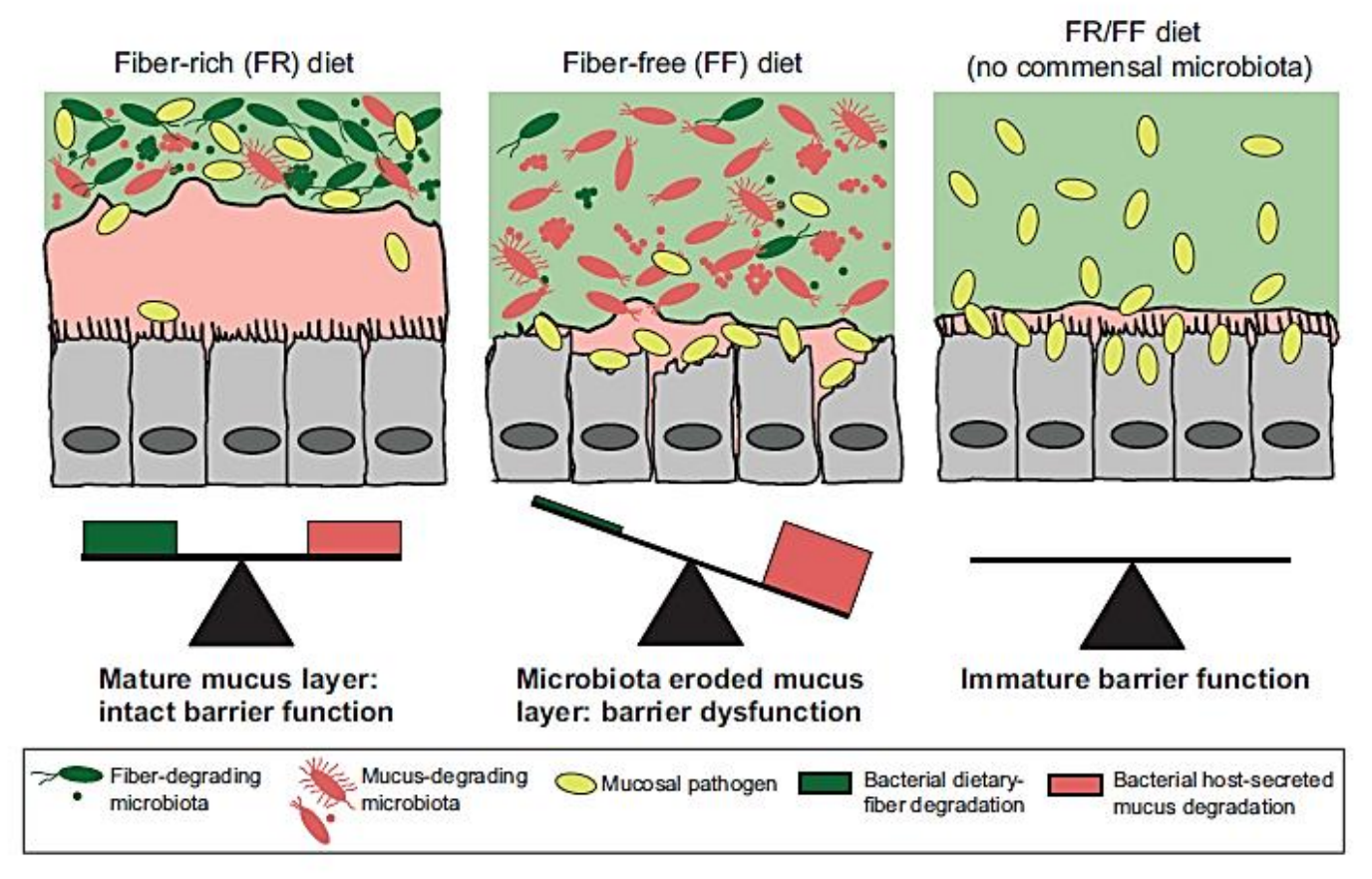

Figure 4: Model of how a fiber-deprived gut microbiota mediates degradation of the colonic mucus barrier and heightened pathogen susceptibility. Reprinted with permission from [127].

\subsection{Diffusion across GI mucus and its implication on drug delivery}

In the case of pig gastric and intestinal mucus, a molecular weight increase (up to $168 \mathrm{kDa}$ ) in peptides or proteins has shown to reduce diffusion $[1,13,128]$. The disruption of the mucus barrier (cleavage of disulphide bond) by mucolytic agent $\mathrm{N}$-acetylcysteine significantly increased permeation of proteins through mucus [13]. Lysozyme diffusion in gastric mucus was slower than in cervicovaginal mucus which shows that differences in mucus properties contribute to this effect [15]. Considering the potential role of proteases found in mucus in peptide/protein digestion, means this can change the overall diffusion, particularly when experiments are conducted using fluorescent markers bound to specific aminoacids [1]. Anionic peptides seem to better diffuse across gastric mucus compared to cationic peptides, however, with a zero net charge is not restricted by mucus, highlighting that charge distribution on the surface of a protein or a particle play a significant role in terms of interactions with mucin [129].

Boegh et al., [14] studied the diffusion of peptide and hormones across biosimilar mucus and porcine intestinal mucus. The biosimilar mucus is composed of mucin, bovine serum albumin (BSA), polyacrylic acid (PAA), cholesterol, phosphatidylcholine and linoleic acid. Both 
biological matrices reduced the permeation of the selected peptides, $<5000 \mathrm{Da}$ (octreotide, desmopressin, vancomycin, novicidin and plectasin) and hormones (estradiol and testosterone) to varying degrees. The reduction in peptide permeation was decreased depending on the cationicity and hydrogen bonding capacity of the permeant as demonstrated in biosimilar mucus. However, there was larger inter sample variation in the porcine intestinal mucus. Testosterone is a small lipophilic molecule and the slight reduction in diffusion could be attributed to its ability to form monovalent, low affinity interactions [130] while other proteins like antibodies or viral enveloped particles may form polyvalent interactions with the hydrophobic parts of mucin thereby greatly slowing their diffusion.

Interestingly, it may seem that colonic mucus due to its greater mucin concentration of $5 \%$ versus $\sim 1 \%$ of ovulatory cervical mucus would prevent non-mucoadhesive particles of 500 $\mathrm{nm}$ from diffusing through the pores of the mucus mesh. However, on the contrary the increased mucin concentration promotes mucin fibre aggregation and therefore increase in mesh size [2].

\section{Sweeping the dirt away: mucosa and mucus of the respiratory tract}

The nasal cavity has an anterior chamber, the nasal vestibule which is followed by the respiratory tract which is highly folded providing a high surface area to volume ratio. The nasal vestibule consists of keratinized stratified squamous epithelial cells and the respiratory regions consisting of the inferior, middle and superior turbinates are made of pseudostratified ciliated columnar cells (Figure 5) with microvilli and cilia thereby providing an area of 120 $\mathrm{cm}^{2}$ [131]. This region produces the maximal nasal secretions because of the presence of seromucus glands, the nasolacrimal duct and goblet cells. This region then progresses into the nasopharynx where the mucus is ingested for destruction of the pathogens $[22,132]$.

The seromucosal glands, which secrete the greater quantity of nasal mucus, comprise both mucus cells; secreting the mucus gels, and serous cells, producing a watery fluid. Approximately 100,000 seromucus glands exist in the human nose and have essentially the same structure as the tracheo-bronchial glands. The number appears to remain constant throughout the life-span indicating that an infant has a secretory capacity comparable to that of an adult, thereby leading to nasal discharge in a child as opposed to an adult in the event of a slight glandular hypersecretion [133]. Accumulation of secretions in the nose may not entirely be due to hypersecretion but probably as a result of reduced mucociliary clearance rate. Viscous secretions can also arise from paranasal sinuses which have numerous goblet cells (pure mucus secretion) and very few glands (seromucus secretions) [134]. 


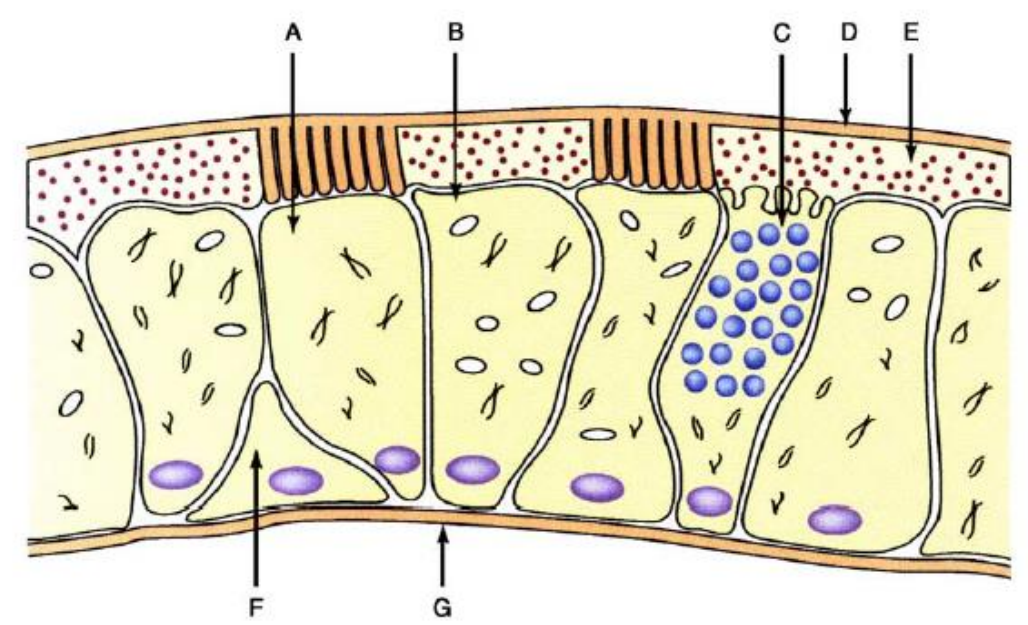

Figure 5: Cell types of the nasal epithelium showing ciliated cell (A), non-ciliated cell (B), goblet cells (C), gel mucus layer (D), sol layer (E), basal cell (F) and basement membrane (G). Reprinted with permission from [22].

About 1.5-2 litres of nasal mucus are produced daily. This mucus blanket consists of two layers: a lower/pericilliary sol phase which is about $6 \mu \mathrm{m}$ thick in which the cilia beat and an upper mucus gel 4-9 $\mu \mathrm{m}$ thick [5]. The viscosity of both layers affects the ciliary beating and the efficiency of transporting the overlying mucus - the mucociliary clearance (MCC). The $\mathrm{pH}$ of nasal cavity varies between 5.5-6.5 in adults and 5.0-7.0 in infants [135].

In the human nose, the goblet cell density of the inferior turbinate ranges from 5,000 to 10,000 cells $/ \mathrm{mm}^{2}$, similar to that of maxillary sinus mucosa. Submucosal gland density ranges from 1000 to 2000 cells $/ \mathrm{mm}^{2}$ in human inferior turbinate and maxillary sinus mucosa. [136]. Membrane-bound mucins have transmembrane and cytoplasmic domains that anchor the molecules to the apical cell membrane where they participate in functions such as structural barrier formation, cellular adhesion, pathogen binding and signal transduction. Extracellular units of membrane-bound mucins can be released from the plasma membrane into the mucus layer by proteolytic cleavage or by shearing forces [137, 138]. In airway epithelial cells MUC1 is a receptor for Pseudomonas aeruginosa flagellin and it also inhibits TLR - 5 (toll like receptor) signalling and IL-8 release. Mucins interact with and inhibit the effects of cationic inflammatory proteins such as leucocyte elastase and lysozyme. The negatively charged carbohydrate of mucins may protect against proteolysis caused by cationic inflammatory proteins and bacterial enzymes [139].

Mucus can crosslink and produce a viscoelastic gel that can form a mechanical coupling with cilia and be transported through them. Nasal secretions are comparably lower in viscosity than tracheobronchial secretions, but a comparable elasticity is more important than viscosity for mucus transport. It is reported that if the sol layer of mucus is too thin, the viscous surface 
layer will inhibit the ciliary beating, and if the sol layer is too thick, mucociliary clearance is impaired because contact with cilia is lost [135].

There are two well differentiated histological regions along the respiratory tract; the conducting airways and the alveolar region for gas exchange which make up for a total surface area of $100 \mathrm{~m}^{2}$ [140]. The conducting airway epithelium (in the trachea, bronchi and bronchioles) is pseudo-stratified and columnar in nature, and is formed by ciliated, basal and secretory cells. Ciliated cells make-up to approximately half of the epithelial surface. The structure of the airway epithelium in the distal bronchioles is more cuboidal and non-ciliated in nature. The protective mucus layer that covers the epithelium also progressively reduces in thickness as the alveolar region is approached, decreasing from a thickness of 10-30 $\mu \mathrm{m}$ at tracheal level, to $2-5 \mu \mathrm{m}$ in the smaller bronchi. Alveolar epithelium consists of type I pneumocytes which are thinner $(0.1-0.3 \mu \mathrm{m})$ to allow efficient gas exchange and type II secrete surfactant, a mixture of phospholipids and proteins which line the alveoli. The main function of surfactant is to avoid alveolar collapse by reducing the surface tension within the alveoli $[6,141]$.

\subsection{Nasal mucociliary clearance and mucins in health and disease}

Cilia beat about 1000 times per minute, with the direction of ciliary beating being backwards thereby conveying the mucus with its trapped inhaled particles (allergens, bacteria, viruses, toxins, etc.) to the nasopharynx for ingestion. This prevents it from reaching the lungs. An optimal movement of cilia combined with mucus rheological properties are required for effective and efficient MCC [56].

The inferior turbinate is the largest of all turbinates. Its length, on average is $48.7 \mathrm{~mm}$ in men, and $47.3 \mathrm{~mm}$ in women [142]. Studies on healthy subject have shown that $80 \%$ exhibit clearance rates of 3-25 $\mathrm{mm} / \mathrm{min}$ (average $6 \mathrm{~mm} / \mathrm{min}$ ) [143]. The mucus lining is renewed approximately every 20 minutes [144]. The mean mucociliary clearance rate in healthy children is $11.1 \pm 3.5 \mathrm{~mm} /$ minute and $12.7 \pm 5.2 \mathrm{~mm} /$ minute for healthy adults (18-60 years) [12]. It was also found that mucociliary clearance rate was reduced to approximately $30 \%$ in comparison to the healthy situation in almost all disease conditions, including chronic sinusitis, allergic rhinitis and also in smokers. An increased ciliary beat frequency and higher mucus production can contribute to increase the MCC. On the other hand, a decrease in mucus viscosity, environmental conditions such as temperatures $\left(</>23^{\circ} \mathrm{C}\right)$, sulphur dioxide inhalation and cigarette smoking can decrease the MCC $[22,145]$.

Nasal mucus is apparently more viscoelastic than tracheobronchial mucus with nasal mucus from healthy subjects exhibiting reducing viscosities at increasing shear frequencies. In patients with rhinitis or bronchitis, the viscoelasticity of nasal mucus decreases dramatically, 
resulting in decreased clearance [146, 147]. Nasal MCC is significantly reduced in chronic sinusitis in both man and rabbit [148]. Viscoelasticity of chronic sinusitis (CS) mucus has been attributed to increased mucin glycoproteins, which was supported by the reduced viscosity but not elasticity of nasal mucus in CS patients treated with mucolytic drugs, such as serratiopeptidase or L-cysteine ethyl ester hydrochloride. The ratio of viscosity ( $)$ to $G$ (elastic modulus) decreased when serratiopeptidase was orally administered to chronic sinusitis patients over a 4 week period thereby increasing the mucociliary transport rate. [16, $149,150]$.

MUC5AC is the predominant mucin in the human airways and its gene expression and production is induced in response to inflammatory stimuli. Bacterial, viral (rhinovirus), chemicals, pollutants, proteases and inflammatory cytokines upregulate mucin gene expression during sinonasal inflammation. Pro-inflammatory cytokines (TNF- $\alpha$, IL-1 $\beta$ ) and Th2 cytokines (IL-4, IL-9 and IL-13), proteases (neutrophil and leucocyte elastase) and histamine stimulate mucin production in vivo [151] and Th2 cytokines and TNF- $\alpha$ alter the glycosylation and sialylation of secreted mucins $[110,152]$. Increased negatively charged mucins have an inhibitory effect against cationic inflammatory proteins and bacterial enzymes, contributing to the defence mechanisms to epithelial injury [139]. On the other hand, mucin overproduction facilitates bacterial adherence, entrapment and removal by mucociliary clearance [36]. It is not yet clear if there are changes in numbers of goblet cells in allergic rhinitis (AR) and chronic rhinosinusitis (CRS). However, the number of submucosal glands doubles in CRS patients and also rabbit models of sinus infection [136, 144]. MUC 5AC and MUC2 are the primarily secreted mucins by goblet cells and MUC5B is secreted by the mucus cells. MUC 2, -5AC (highest contribution) and $-5 \mathrm{~B}$ expressions are upregulated during airway inflammation (allergic rhinitis and chronic sinusitis) in humans. [153].

In a study by Voynow and colleagues, superficial nasal epithelial cells from normal, cystic fibrosis $(\mathrm{CF})$ and allergic rhinitis individuals were used to study the expression of the mucin genes MUC5/5AC, MUC2 and MUC1 [154]. These are the preferred cells due to their similarity in expression of the CFTR mRNA at levels equivalent to the lower respiratory epithelium and free from infection and chronic inflammation. MUC5/5AC gene expression was greater than MUC2/MUC1 for all subject groups. In addition, in situ hybridization studies revealed that MUC1, MUC2, and MUC5AC genes are expressed primarily in the superficial epithelium of nasal turbinates, an expression pattern similar to that of the lower respiratory tract [155]. MUC2 mRNA levels were similar among subject groups although these results differed from another study by $\mathrm{Li}$ and co-workers who suggested increased levels of MUC2 mRNA in CF nasal cells compared with controls [9]. This difference can be attributed to the fact that all CF subjects in the study by Li et al. were enrolled in a gene therapy trial and had received either CFTR cDNA - liposome complexes or liposome alone by topical application to the nose [154]. 


\subsection{Challenges in nasal drug delivery}

Despite the advantages in nasal drug delivery, limitations exist that must be considered in the potential delivery of drugs through this route. The movement resulting from mucociliary clearance inhibits drug absorption since contact of formulations with the absorptive surface is dramatically reduced. Calcium depletion or blocking calcium activity leads to loss of ciliary beating, decreasing clearance. This has a strong implication in nasal mucoadhesive drug delivery. Some mucoadhesive polymers like polyacrylic acids chelate calcium ions and lead to reduced CBF and longer MCC time [156]. The nature of the mucus barrier also limits drug diffusion and potential absorption. The low fluid volume of the nasal cavity restricts the potential volume that can be administered to $100-150 \mu 1$, posing problems to the administration of high doses of poorly water-soluble drugs [157]. Techniques have been used to overcome these obstacles, including synthesis of more soluble prodrugs, use of penetration enhancers or use of bioadhesive polymers and protease inhibitors to increase the permeability of the mucosa to the drug, increase residence time within the nasal cavity and to protect against enzymatic degradation [158]. Furthermore, an animal model closest to humans in terms of administration volume and clearance rate is also necessary, and the Beagle dog's nasal parameters seem closest to meet these requirements [159]. 


\subsection{Lower respiratory mucus and mucins in health and disease}

In the conducting airways of the lung, the mucus barrier possesses gel-sol characteristics and is organized in two differentiated layers. The upper layer of the mucus, exposed to the airway lumen, presents a high viscosity (gel) and acts as a potent sticky filter for inhaled particulate matter. On the other hand, the lower layer, also termed the periciliary fluid, is considered a watery (sol) layer and is known as gel on liquid layer [160] This layer allows the cilia to beat and recover, so that the rather thick mucus blanket can be propelled towards the proximal airways for gastric clearance [160, 161]. Mucociliary clearance rates of $10-100 \mu \mathrm{m} \mathrm{s}^{-1}$ have been measured in the human trachea and the thickness of about 10-30 $\mu \mathrm{m}$ is justifiable by the small quantity, $10 \mathrm{ml}$ of mucus secreted each day [162,163]. The clearance of inhaled foreign matter trapped within the mucus gel occurs in 15 minutes to 2 hours after inhalation [164].

Five major mucins are expressed in the airways: MUC1, MUC4, MUC5AC, MUC5B, and MUC16 [37]. Of these, MUC1, MUC4 and MUC16 are cell membrane bound mucins. Some of the proposed roles for membrane-associated mucins include intracellular signal transduction pathways, control of inflammation and immune responses, and regulation of cell differentiation and proliferation. On the other hand, MUC5AC and MUC5B are the most important secreted mucins of the airways and secretion is modulated by inflammatory factors such as neutrophil elastase, bacteria, and cytokines [5]. MUC5AC is produced and secreted by goblet cells [165], whereas MUC5B is mainly produced by submucosal glands [37]. MUC7, a small mucin that lacks domains and does not form a gel, is secreted by a subset of serous cells in submucosal glands [166]. The gel-forming MUC5AC and MUC5B are primarily responsible for the viscous nature of the luminal mucus mesh which has viscosity about 10,000 times higher than that of water [37, 160, 167].

Additionally, a gel on brush model has been postulated in which the pericilary layer (PCL) is occupied by membrane spanning mucins and mucopolysaccharides densely tethered to the airway surface. In this model, MUC1 is at the bottom of the PCL while MUC4 spans the entire PCL giving it a brush like appearance. This prevents mucus penetration and entry into the periciliary space. The gel on liquid layer does not explain why the MUC 5AC and MUC 5B with hydrodynamic radii of $\sim 150-200 \mathrm{~nm}$ do not penetrate into the $\sim 200 \mathrm{~nm}$ interciliary space to form a single layer. In fact, this interciliary space is impenetrable to objects significantly smaller than mucins including fluorescent beads of $40 \mathrm{~nm}$ diameter [5].

An increase in the viscoelasticity of mucus is usually found in patients with pulmonary disorders such as cystic fibrosis, chronic obstructive pulmonary disease (COPD) and asthma, resulting from decreased hydration and increased fraction of mucins and DNA. In contrast, there is a decrease in viscoelasticity in those suffering from rhinitis or bronchitis. The mucociliary clearance is the primary mechanism for airway clearance of mucus and is highly dependent on the viscoelasticity of the mucus and hydration of the periciliary layer. An 
intermediate viscoelasticity of the mucus gel and a low viscosity perciliary (sol) layer are essential for optimal mucociliary transport [168]. During the ciliary movement a high shear rate lowers the viscosity of the mucus hence facilitating its efficient transport. However, if the viscoelasticity of the mucus becomes too low, such that the elasticity is insufficient for the mucus to withstand gravitational pulling, the mucociliary clearance gets affected and mucus slides down into the lung and floods the alveoli. In contrast, when lung disease develops, it leads to the development of highly viscoelastic mucus layer and depletion of the sol layer. Therefore, the sweeping force exerted by the cilia is incapable of transporting the thick mucus and mucociliary clearance ceases, thereby plugging the smaller airways and initiating cough reflex as a primary means of transporting mucus upwards [169].

Cystic fibrosis (CF) occurs due to mutations in the CFTR gene. This leads to decreased epithelial sodium channel $(\mathrm{ENaC})$ activity decreasing sodium concentration in mucus and bicarbonate required for its release and normal viscoelasticity. One theory describes airway dehydration as a result of an increase in the mucus osmotic pressure being greater than periciliary layer (PCL). Mucus draws water from PCL and beyond a certain concentration, the osmotic pressure exceeds that of PCL, initiating the collapse of PCL. In this scenario, cilia are unable to beat effectively, mucus adheres to the epithelium causing MCC to cease. Mucus stasis leads to airway plugging, chronic bacterial infection, further inflammation and airway tissue damage (bronchiectasis) [45].

Mouse models have revealed that MUC5AC provides protection against viral infection by acting as a decoy for viral receptors, while MUC5B is essential for MCC and controlling bacterial infection [45]. Analysis of CF sputum mucin content has revealed increased MUC5AC and MUC5B concentrations (especially following exacerbations) with MUC5B being the predominant mucin [170]. Likewise, immunohistochemical analysis has demonstrated increased concentrations of MUC5AC and MUC5B in the mucus plugs of CF airways when compared to healthy controls, again, with a higher relative abundance of MUC5B [171]. In human tissues, histochemical observations showed increased MUC5AC and MUC5B staining of goblet cells and mucus cells of submucosal glands respectively, with an increase of MUC5AC-positive cells due to goblet cell hyper and metaplasia [172]. However, results suggest that CF airway inflammation occurs even in children under 6 months and could even precede infection. Increased amounts of neutrophils, neutrophil elastase and pro-inflammatory cytokines (IL-8) can be detected in broncho-alveolar lavage (BAL) [173]. BAL and sputum from adults also contain pro-inflammatory cytokines such as TNF- $\alpha$, IL-1, IL-6, IL-8 and IL-17 compared to non-CF controls [174,] whereas antiinflammatory cytokine IL-10 is reduced [175]. Aberrant ion transport and mucus dehydration are not the main causes of inflammation and therefore a mechanism inducing this inflammation has been investigated. Mutation in the CFTR leads to accumulation of misfolded CFTR, resulting in nuclear factor-kB activation and increased IL-8 even in the absence of bacteria [176]. In human bronchiolar mucosa, TNF- $\alpha$ increases expression and activity of sialyltrasferases and sulfotransferase. This can explain the over sialyation on human airway mucins secreted by patients with severe lung infections such as those with CF. 
Increased IL-6 and IL-8 also increase expression of sialyl transferase, fucosyl transferase genes thereby contributing towards increased sialylation and sulfation of airway mucins promoting the increased adhesion of Pseudomonas aeruginosa. This coupled with increased mucus viscosity, periciliary collapse and stasis leads to lung infection [110, 177, 178].

Certain diseases and smoking affect the glycosylation of mucins. Exposure to cigarette smoke which leads to chronic obstructive airways disease, causes a shift from an almost equal proportion of acidic and neutral mucins to mostly neutral mucins [162].

\section{Is the cervical and vaginal mucus similar?}

The cervix connects the vagina with the uterus and functioning as an entrance into the female endometrial and abdominal cavities. Therefore, a protection mechanism has to be in place to avoid external microorganisms to gain access. The vagina wall is structured in a lamina propria and an epithelium of non-cornified stratified squamous cells. The thickness of this epithelial barrier is higher in puberty and after menopause. The luminal $\mathrm{pH}$ decreases after puberty to about $\mathrm{pH} 4-5$, depending on the menstrual cycle. The secreted cervical mucus fills the opening of the cervix and acts as an important protective barrier preventing pathogens from ascending into the uterus. Secreted into the vagina, the mucus is also important as it traps microorganisms and flushes these out of the vagina to protect both the uterus and the vaginal epithelium. Despite its protective role, the mucus should allow or serve on the other hand as vehicle for sperm to migrate at ovulation [179].

\subsection{Mucins of the cervix and vagina}

The cervical mucus is a complex secretion originating from the secretory cells of the columnar epithelium of the cervix. Mucus facilitates the sperm movement from the vagina till the uterus. It has been shown that the hydration of the mucus, rheological properties and glycosylation play a major role on this process. The carbohydrate content of mucin during the menstrual cycle seems to be preserved but soluble proteins show a variation along this timescale. The secretion rate reaches its peak during the middle of the cycle [180]. The secretion of cervical mucus is regulated by the ovarian hormones estrogen and progesterone. While the first promotes mucus production the latter inhibits the secretory activity of the cervical epithelial cells [181].

Mucins form a highly viscoelastic mesh acting as a lubricant and a physical barrier for microbes at mucosal interfaces [3]. Mucosal epithelial cells express cell surface mucins, such as MUC1, MUC4, and MUC16 [76]. Goblet cells produce and secrete gel-forming mucins, such as MUC5AC, MUC5B, and MUC6. Both type of mucins, cell-surface and secreted are found in the mucus in the endocervix. Besides the cervical mucus, which flows into the 
vaginal compartment, the cervicovaginal fluid is composed by vaginal wall transudate, vulvar secretions, exfoliated epithelial cells, and secretions from bacterial flora [182]. This mixture of cervical mucus and cervicovaginal fluid is designed as cervicovaginal mucus (CVM). In consequence of the different composition is likely that the mucin structure and barrier function in CVM differs from that in CM secreted at the endocervix $[182,183]$.

The cervical and cervicovaginal mucus play a major role in protection against infections, such as those by HIV, by hindering diffusion to the epithelial surface. It has been found that cervicovaginal fluid interacts with HIV, favoured at neutral $\mathrm{pH}$ (compared to acidic $\mathrm{pH}$ ), but not with $200 \mathrm{~nm}$ Pegylated nanoparticles, highlighting the role of lipids and proteins in virus on interaction with the protein core of mucins [182]. However, the permeation of pegylated particles is also hindered in cervical mucus, suggesting a much more dense mucus network. Water content, mucin expression levels, and glycosylation vary throughout the cycle in CM [179].

Genotypic differences between individuals that affect the number and type of carbohydrate residues on mucins also play a role on protection against pathogens [3]. The viscoelastic properties of CM slow down diffusion of HIV-1 increasing the time available for innate immune factors to inactivate the virus. Additionally, the mucus movement towards the vagina allows clearance of mucus form the cervical canal in around 24 hours [184, 185].

\subsection{Mucin and mucus changes during menstrual cycle and disease}

The cervix produces about 20-60 mg mucus/day in normal women at reproductive age, however, during the midcycle this amount is increase up to $700 \mathrm{mg}$ mucus/day [181]. Despite changes in quantity, also physical characteristics such as viscosity and mucin glycosylation undergo changes during midcycle. For instance, viscosity and flow elasticity are reduced after menstruation to the ovulation time $[179,186]$. In fact, altered mucus properties have been shown to be a very good predictor of the fertile window [186]. The importance of the cervical mucus is also illustrated by the observation that abnormalities of the cervical secretions are responsible for infertility in about $5-10 \%$ of infertile women $[181,186]$. Despite its importance, there is still limited biochemical understanding of the composition of the cervical mucus and how this is altered during ovulation. Most of the cervical mucus is water (95$99 \%$ ), but it also contains a complex mixture of organic components, inorganic ions, enzymes, bactericidal proteins, plasma proteins, and especially mucins. In the mucus 2 types of proteins can be found: soluble proteins, predominantly albumin and immunoglubulins and mucins. During the pre and post-ovulation it has been found an increase of these soluble proteins in mucus. Other proteins, such as the enzymes amylase, alkaline phosphatase, esterase, aminopeptidase, lactate dehydrogenase and peroxidase can also be found in the cervical mucus [186]. 
In the cervical mucus the gel-forming mucin MUC5B is the major mucin component together with MUC5AC. The amount of MUC5B mucin in human cervical mucus varies during the menstrual cycle and peaks at ovulation, suggesting that this larger mucin species may be an important factor affecting sperm transit to the uterus [187]. All mucins contain large mucin domains, also called PTS domains, that are rich in the amino acids serine, threonine, and proline and provide a high number of attachment sites for $O$-linked carbohydrates [187], which contribute to the rheological and hydrodynamic properties of mucins. Changes in mucin glycosylation during ovulation can lead to modifications in other biochemical properties but conflicting results have been reported [188, 189].

A more recent and comprehensive study showed that the $O$-glycans of the cervical mucins exhibited more than 50 different neutral, sialated, and sulfated oligosaccharides [179]. The major changes observed during the menstrual cycle were in the mucin $O$-glycosylation and at ovulation. This was reflected by a relative abundance of neutral oligosaccharides in comparison to those acidic. The mucus glycosylation at ovulation could also promote sperm movement due to the low sialic acid content of the mucus. Although the composition of the mucus seems to be relatively constant, except for the mucin glycosylation, other alterations in mucins could contribute to the altered mucus properties.

\subsubsection{Cervical mucus role in fertility and disease}

Cervical mucus and $\mathrm{pH}$ plays a role in sperm survival and fertility. In order to maintain sperm viable the optimal $\mathrm{pH}$ ranges between 7 and 8.5 with a reduction in motility seen for $\mathrm{pH}$ below 6 . Since the cervical $\mathrm{pH}$ is acidic, the higher $\mathrm{pH}$ of the semen associated with its buffer capacity contributes to the viability of sperm. However, reduction of semen volume or $\mathrm{pH}$ can affect fertility. Cervical mucus changes can also dramatically affect mobility of sperm along the cervical canal $[57,190]$. For instance, in chronic cervicitis, the mucus composition is changed affecting its structure and thereby impacting sperm movement between the mucus mesh [57]. The cervical mucus architecture is not uniform presenting areas of tighter mucus mesh, closer to the mucosa and looser mucus regions where shear is higher [190]. Lactobacillus species, particularly Lactobacillus iners, is the most abundant bacteria in the vagina of premenopausal women [191]. These bacteria produce lactic acid, hydrogen peroxide and other antimicrobial molecules which protect against vaginal infections [192, 193]. L. iners feed on glycan from degraded mucin [192].

Bacterial vaginosis is a common condition, being mostly asymptomatic. Malodorous is the only signal of this condition, reflected by lower levels of Lactobacilli and overgrowth of anaerobic and facultative bacteria [191]. A disruption in the mucus architecture, as seen in cases of bacterial vaginosis, allows diffusion of virus leading to potential infections [182, 194]. Different species of Lactobacillus contribute to the diffusion properties of cervicovaginal mucus having a significant role on protection against HIV and other sexually transmitted infections [195]. Therapeutic interventions leading to re-establishment of lactobacilli, for instance, through probiotic or by products that reinforce lactic acid can 
contribute to a protections against infection [193]. Candida albicans bind to fucosylated glycans highlighting the role of these mucins in protection against Candida albicans infections [196].

\subsection{Diffusion across cervical mucus and means to overcome it for improved drug delivery}

In contrary to early observations, virus and large proteins are able to diffuse across mucus $[15,197]$. Diffusion of particles, virus and proteins through mucus is dependent on mucus mesh size and interactions with the glycoproteins, which can hinder movement within the network [31]. For an effective immune surveillance, the antibodies present in the mucus shall be able to move freely within the mucus mesh to neutralize pathogens. Large complexes of antigen-antibody can then be removed with the renewal of the mucus. Also topical delivery of antibodies to protect against sexually transmitted diseases or fertilization has been proven as an useful strategy [197]. Similarly, antibodies directed against intestinal pathogens have shown a protective function of the underlying epithelium [198]. In human midcycle cervical mucus samples, the diffusion coefficients of most of the tested fluorescent labelled proteins (exogenous), including IgG were similar to diffusion coefficients in buffer, indicating a lack of barrier function given by the mucus [15, 197]. However, IgM diffusion is significantly slowed down in mucus, as well as IgM without the respective Fabs, suggesting that the Fc region is the main responsible for the low binding affinity to mucins [15].

Others have demonstrated that a fraction of endogenous IgG and IgA can differentially bind to cervical $(\mathrm{CM})$ and cervicovaginal mucus $(\mathrm{CVM})$. IgG is found to be stable associated with both CM and CVM whereas IgA is not associated with CVM [199]. This suggests that the number of binding sites may be limited, explaining why exogenous applied IgGs can diffuse quickly through cervical mucus. In the gastrointestinal tract, binding of IgG can occur by direct binding to mucins or through binding to FcGBP present in the mucus [200, 201]. The binding of IgG to mucins can contribute to the entrapment of pathogens such as HIV, being shed with the mucus renewal and preventing an infection of the underlying epithelium. Surprisingly, even capsid virus-like particles such as human papilloma virus $(55 \mathrm{~nm}$, $20000 \mathrm{kDa}$ ) and Norwalk virus (38 nm, $10000 \mathrm{kDa}$ ) diffuses unhindered through cervical mucus. In contrast, diffusion of herpes simplex virus $(180 \mathrm{~nm})$ is strongly reduced in cervical mucus, suggesting that besides a mesh size of mucus, also a low binding affinity with mucins contributes to this effect. Furthermore, polystyrene particles $(1000 \mathrm{~nm})$ have been shown to bind strongly to mucin, hindering diffusion. It has been suggested that a combination of positive and negative charges prevents adhesion on the surface of proteins plus lack of hydrophobic exposed regions [202] .

Among the conventional vaginal drug delivery systems are vaginal tablets, foams, gels, suspensions and vaginal rings. The latter have been developed to deliver the contraceptive 
steroids in a sustained release fashion [191]. The complex interactions between mucins and other molecules and fast diffusion of virus particles with neutral net charges have inspired the design of novel carrier systems with improved diffusion through mucus in order to increase bioavailability and decrease degradation in the luminal conditions [15]. In this regard, mucus penetrating particles, exhibiting a surface densely covered with polyethyleneglycol have been developed [17, 203]. The lower molecular weight and higher density of PEG on the surface resulted in faster diffusion rate in human cervicovaginal mucus [204]. Ex-vivo and in vivo rapid diffusion through mouse vaginal and colorectal mucus has been observed with nanoparticles grafted with PEG with $40 \mathrm{kDa}$ [205]. Furthermore, it has been shown that hypo tonicity of the applied formulation improves distribution and diffusion of the particles through the cervicovaginal mucus [206, 207]. On the other hand, it has been recently highlighted the possibility to generate anti-PEG IgG and IgM, which can cross-link PEG coated particles limiting its diffusion through mouse cervicovaginal mucus, even when the particles are prepared as hypotonic suspension [208].

\section{Protecting the sclera: the pre-corneal tear film and conjunctival epithelium}

The eye (figure 6) is covered by a wet surface epithelium over coating the cornea, conjunctiva and other inner surfaces, which has similar functions as other wet surfaces, including lubrication, protection against damage, fluid loss and pathogens infection [209, 210]. The epithelium of the cornea also plays a role in the transmission of light and refraction. The tear film is composed by an outer lipid layer and by the inner aqueous layer which is composed by anti-bacteria proteins and mucins. Besides contributing to retain water, mucins also function as a retention mesh to bacteria and particles to protect the underlying epithelium [209]. Additional functions such as barrier function, cell growth and differentiation, cell-cell and cell-matrix interactions, and signal transduction have been attributed to ocular membrane-associated mucins [39, 211].

The cornea surface is layered by a non-keratinized stratified squamous epithelium, disposed in regular 5-7 cells layers, highly specialized in light reflections and transmittance, and in rats it is renewed within 7 days, as a consequence of migration of basal cells to the apical layer [212].

\subsection{Formation of the tear film}

The epithelium of the conjunctiva coats the inner surface of the eyelid and is similar in structure to the corneal epithelium, however the numbers of cell layers ranges between 3 and 12 [209]. Intercalated in between the epithelial cells are Goblet cells, in higher numbers in humans near the exit of the nasolacrimal duct [213]. Goblet cells of the conjunctiva extend throughout the thickness of the stratified epithelium to the apical surface, where MUC5AC is 
released. MUC5AC, a heavily glycosylated mucin is released from the mucin granule in a mechanism dependent on high concentration of cations, such as calcium. In contrast to the mucins in the gut, MUC5AC at the ocular surface does not form a continuous layer but moves over the surface of the epithelium. MUC 16, a transmembrane mucin seems to play a role in MUC5C discharge [214]. Goblet cells form tight junctions with stratified epithelial cells and express claudin 2, a pore-former type of claudin which has been suggested to be involved in the regulation of fluid to and from the tear film [214]. While in rats and mice, there are clusters of Goblet cells, in rabbits and humans they are found isolated [215]. The submucosal lacrimal glands and Meibomian glands (in the lid) are responsible for the secretion of the lipid layer of the tear film [213].

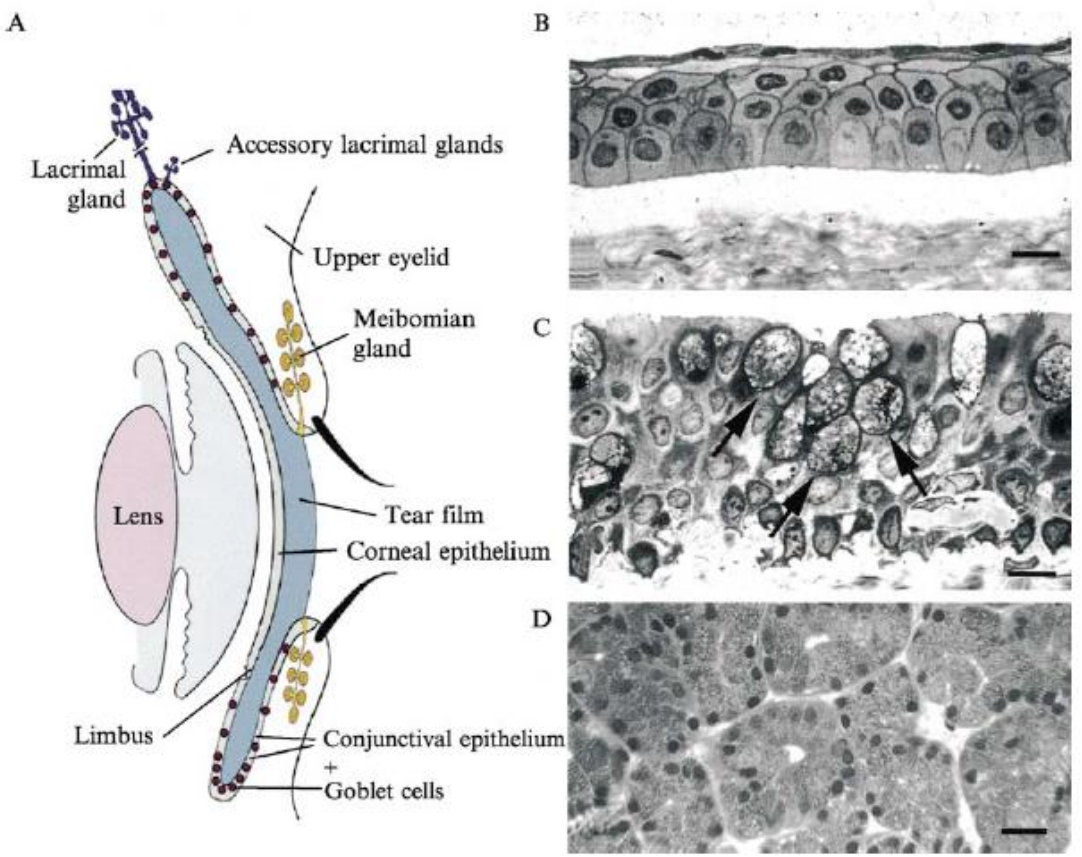

Figure 6: Diagram of the anterior portion of the eye (A), stratified epithelium of the cornea (B), stratified epithelium of the conjunctiva (C), epithelia of the lacrimal gland (D). Reprinted with permission from Gibson, 2003 [209].

The human ocular surface produces two secreted mucins, the gel-forming MUC5AC and the soluble MUC7 [216]. The goblet cells of the conjunctiva epithelium contribute the most to the secreted mucins present in the tear film. 


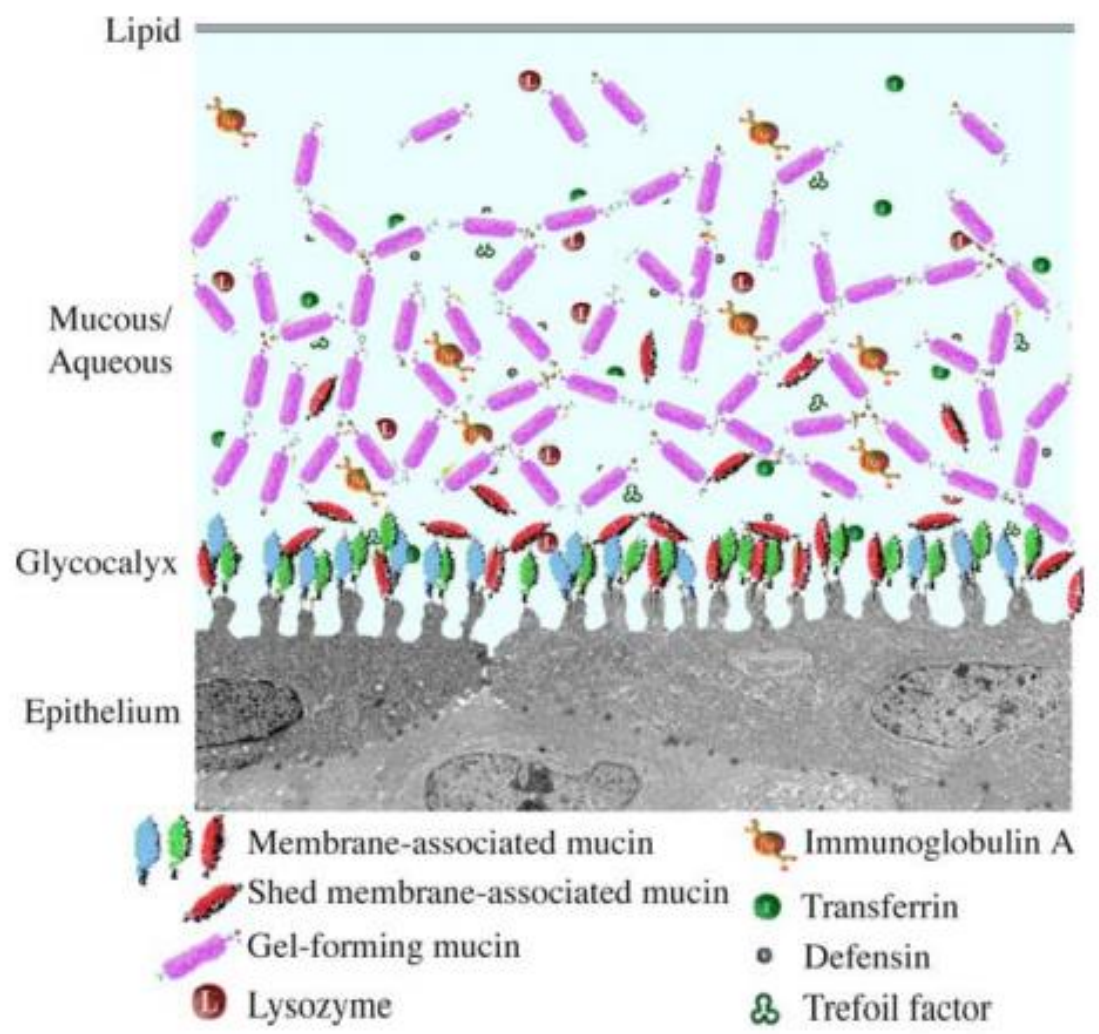

Figure 7: Diagram of the tear film and its interface with the ocular surface epithelium. Reprinted with permission from [217].

The transmembrane mucins, MUC1, MUC4, and MUC16, have been found at the ocular surface [39, 210], namely at the most apical side of the stratified squamous epithelium of the cornea and conjunctiva. Other mucins have been also observed on the human conjunctiva, such MUC13, MUC15, and MUC17 [211]. MUC20, a transmembrane mucin was found on the extent of the corneal and conjunctiva epithelial cells and is involved in keeping the ocular surface homeostasis [211]. Among the gel-forming mucins, MUC5AC (the most abundant), MUC2 (less abundant) is produced and secreted by the goblet cells of the conjunctiva while the soluble MUC7 is produced by the lacrimal gland and by the stratified epithelium of the conjunctiva [216, 218, 219]. The lacrimal gland besides MUC 7 also produces other mucins, such as MUC1, MUC4, MUC5AC, MUC5B, MUC6 and MUC7, whose levels seem to change with age [220].

\subsection{Ocular mucins in health and disease}

The apical membranes in the cornea and conjunctiva show fingerlike ridges (microplicae) which increases its surface area covered with the glycocalyx, extracellular domains of the membrane associated mucins [213]. The mucus component (secreted mucins plus membrane 
bound mucins have been estimated to be $3-30 \mu \mathrm{m}$ thick in different animal models using confocal microscopy and interferometry [221]. The secreted mucins move freely contributing to lubrication and removal of foreign particles from the surface of the eye. During blinking, the mucus and tear film eventually move out towards the nasolacrimal duct [209]. Similarly, membrane bound mucins are shed off as the epithelial cells age and the microplicae structure is lost [213].

The secreted mucins MUC5AC and MUC 7 contribute to the lubrication and protection of the epithelial by binding fungi and yeast and to remove particulate material away [209]. MUC7 also facilitates the transportation of bactericidal proteins from the lacrimal gland to the tear film [216]. It is not completely understood if the different membrane bound mucins share functions or each is responsible for a particular function. These mucins contribute to water retention at the surface of the cornea and conjunctiva and also to lubricate, promoting disadhesion, and avoiding strong interactions between the eye lid conjunctival epithelium to the cornea. Due to its less dynamic nature, they provide a continuous protective barrier against pathogens [39, 213]. MUC1 and MUC 4 seems to be also involved in signal transduction and growth control [188].

Changes in mucins at the ocular surface during expression, translation or post-translational (i.e. glycosylation) often leads to allergic, non-autoimmune dry eye, autoimmune dry eye and infections [39]. In the case of allergic diseases, such as atopic keratoconjunctivitis (AKC) and vernal keratoconjunctivitis (VKC), changes occur in both types of mucins. Patients with atopic keratoconjunctivitis exhibit a loss of Goblet cells and decreased levels of MUC5AC and increase in expression of MUC1, MUC2 and MUC 4 [222, 223]. Reduced levels of expressed MUC16 have also been reported in atopic keratoconjunctivitis [222]. Using a mouse model of allergic conjunctivitis a lower number of Goblet cells and MUC5 was found in the conjunctiva after repetitive application of allergens [224]. On the other hand, an increased level of Goblet cells and increased amounts of MUC5AC is a landmark of vernal keratoconjunctivitis as an over-response to clear-up allergens from the ocular surface. This is accompanied by ocular inflammation and neutrophils infiltration [225] .

Drying or keratinization of the ocular surface, such as manifested in dry eye syndrome (aqueous or lipid deficient and the Sjögren syndrome) [39, 209, 223, 226] find their roots in alterations at the mucin level. Expression of MUC4, MUC5AC and MUC5B was found to be higher in the glands of elderly women receiving treatment for dry eye as compared to the absence of treatment [227]. Furthermore, reduced Goblet cells and reduced levels of MUC5AC in the tear fluid and conjunctiva have been reported in patients with Sjögren syndrome, a systemic autoimmune disease, most prevalent in women [226]. Also, MUC19 has been reported to be reduced [228]. Interfering with the mechanism of membrane bound and secreted mucin expression to promote expression could offer therapeutic advantages in the treatment of dry eye syndrome [229]. Also, diseases leading to cicatrization such as the ocular cicatricial pemphigoid and Stevens-Johnson syndrome can be caused by changes in 
mucins. Alteration of O-glycosylation of mucins, due to changes in glycosyltransferases has been reported as a cause for ocular cicatricial pemphigoid [230].

\subsection{Implications of ocular mucins on drug delivery}

Drug delivery to the eye offers the advantage of the easy access for application, however due to the anatomy and rapid blinking and tear drainage, the residence time of the drug at the absorbing surface, mostly the cornea, bioavailability and delivery to the posterior segment of the eye is limited [231]. The clearance of topically applied solutions occurs within 15 to 30 seconds. Therefore, the resulting intraocular bioavailability of topically applied drugs to the anterior chamber is less than 5\%. The cornea is structured into the epithelium, stroma, rich in water and endothelium. Most of the drugs delivered to the eye are drops, ointments, hydrogels and extended release devices, such as contact lens for local action [232]. Absorption through the conjunctiva offers an entry into the bloodstream. The cornea and conjunctiva are covered with the tear fluid, which besides secreted mucins contains electrolytes, albumin and lysozyme and on its top lays a lipid barrier (secretion by the Meibomian glands). In normal conditions, only a very small volume of administered drugs, circa $30 \mu$, can be applied without overflowing [232, 233]. The composition of eye drops can enhance tear flow reducing drug concentration at the epithelium. Increasing the viscosity of eye drop vehicles, using polymers that can also bind to mucins of the eye drops vehicle can have a positive impact on drug retention, however the effect is limited [234]. The secreted mucins do not form a static mucus layer on top of the cornea and therefore retention of the formulation is limited by the shed-off of mucins along with the tear fluid. Soft contact lenses have also been used to deliver drugs to the ocular surface and is reviewed elsewhere [232, 235, 236]. Mucin expression is not altered by long term contact lens wearing, however both shed transmembrane and secreted mucins can adhere to contact lens [237]. An optimal ocular delivery system should allow zero-order release kinetics, cause minimal inflammation and irritation, minimal loss in the storage process, easy handling and have the least interference with the patient's vision. Kala Pharmaceutics is developing ocular formulations based on mucus penetrating particles, which are able to rapidly penetrate the mucus and avoiding clearance, increasing the exposure to the epithelial cells. The concept has been successfully demonstrated in both rabbits and minipigs, resulting in therapeutic drug levels in the back of the eye [238-240].

\section{Conclusion}

This review has served to highlight the adaptations of mucosal surfaces and mucus to promote their optimal and healthy functioning. Factors including mucus hydrophobicity, viscoelasticity, turnover and thickness, as well as epithelial dynamics (such as mucociliary clearance in the respiratory tract) work together to enable mucus to function as a tenacious 
semi-permeable barrier. However, this useful mucus barrier can also create a slippery slope of challenges to mucosal drug and gene delivery leading to poor local or systemic uptake. Therefore, an understanding of its origins, physiology, biochemistry and the nature of the epithelia bears importance and has been the key focus of this review. This fundamental information will enable effective drug delivery systems to be designed, enhancing drug penetration through the mucus barrier to reach the underlying epithelia. There is no single factor that can be overcome to easily promote the increased penetration of drugs or delivery systems through the overlying epithelial mucus barrier. However, attempts have been made to circumvent these limitations: mucophilic nanoparticles have shown promise in terms of fast diffusion rates through the mucus layer. However, their ability to beat the rate of secretion and travel upstream to reach, adhere and sufficiently deliver the payload or penetrate the epithelium is yet to be understood. Furthermore, virus mimetic mucus-penetrating nanoparticles have been designed for cervico-vaginal and ocular delivery. It is clear that by gaining a detailed understanding of the mucus barrier, more effective mucosal drug delivery systems can be designed, resulting in rewarding outcomes in terms of desired efficacy rates compared to currently failing efforts.

\section{Acknowledgements}

We thank Atheer Awad for assisting with the technicalities involved in preparing the graphical abstract.

\section{Funding source}

This research did not receive any specific grant from funding agencies in the public, commercial, or not-for-profit sectors.

\section{Declaration of interest}

'Conflicts of interest: none'. 


\section{References}

1. Boegh, M. and H.M. Nielsen, Mucus as a barrier to drug delivery - understanding and mimicking the barrier properties. Basic Clin Pharmacol Toxicol, 2015. 116(3): p. 179-86.

2. Cone, R.A., Barrier properties of mucus. Advanced Drug Delivery Reviews, 2009. 61(2): p. 75-85.

3. Linden, S.K., et al., Mucins in the mucosal barrier to infection. Mucosal Immunol., 2008. 1(3): p. 183-197.

4. $\quad$ Ensign, L.M., et al., Ex vivo characterization of particle transport in mucus secretions coating freshly excised mucosal tissues. Molecular pharmaceutics, 2013. 10(6): p. 2176-2182.

5. Button, B., et al., A Periciliary Brush Promotes the Lung Health by Separating the Mucus Layer from Airway Epithelia. Science, 2012. 337(6097): p. 937-941.

6. Murgia, X., et al., Overcoming the pulmonary barrier: new insights to improve the efficiency of inhaled therapeutics. Eur. J. Nanomed, 2014. 6(3): p. 157-169.

7. Johansson, M.E.V., et al., The inner of the two Muc2 mucin-dependent mucus layers in colon is devoid of bacteria. Proceedings of the National Academy of Sciences of the United States of America, 2008. 105(39): p. 15064-9.

8. Allen, A. and G. Flemström, Gastroduodenal mucus bicarbonate barrier: protection against acid and pepsin. American Journal of Physiology - Cell Physiology, 2005. 288(1): p. C1-C19.

9. Linford, E., Cervical mucus: an agent or a barrier to conception? J Reprod Fertil, 1974. 37(1): p. 239-50.

10. Flint, H.J., et al., Microbial degradation of complex carbohydrates in the gut. Gut Microbes, 2012. 3(4): p. 289-306.

11. Tailford, L.E., et al., Mucin glycan foraging in the human gut microbiome. Front Genet, 2015. 6: p. 81.

12. Johansson, M.E.V., et al., Bacteria penetrate the normally impenetrable inner colon mucus layer in both murine colitis models and patients with ulcerative colitis. Gut, 2014. 63(2): p. 281-91.

13. Bernkop-Schnürch, A. and R. Fragner, Investigations into the Diffusion Behaviour of Polypeptides in Native Intestinal Mucus with Regard to their Peroral Administration. Pharmacy and Pharmacology Communications, 1996. 2(8): p. 361-363.

14. Boegh, M., et al., Steric and interactive barrier properties of intestinal mucus elucidated by particle diffusion and peptide permeation. Eur J Pharm Biopharm, 2015. 95(Pt A): p. 136-43.

15. Olmsted, S.S., et al., Diffusion of macromolecules and virus-like particles in human cervical mucus. Biophys J, 2001. 81(4): p. 1930-7.

16. Lai, S.K., et al., Micro- and macrorheology of mucus. Advanced Drug Delivery Reviews, 2009. 61(2): p. 86-100.

17. Lai, S.K., Y.Y. Wang, and J. Hanes, Mucus-penetrating nanoparticles for drug and gene delivery to mucosal tissues. Adv Drug Deliv Rev, 2009. 61(2): p. 158-71.

18. $\quad \mathrm{Xu}, \mathrm{Q}$., et al., Impact of Surface Polyethylene Glycol (PEG) Density on Biodegradable Nanoparticle Transport in Mucus ex Vivo and Distribution in Vivo. ACS Nano, 2015. 9(9): p. 9217-27.

19. Varum, F.J., et al., Mucoadhesion and the gastrointestinal tract. Crit Rev Ther Drug Carrier Syst, 25 (3) pp. 207-258. (2008), 2008.

20. Netsomboon, K. and A. Bernkop-Schnürch, Mucoadhesive vs. mucopenetrating particulate drug delivery. European journal of pharmaceutics and biopharmaceutics : 
official journal of Arbeitsgemeinschaft für Pharmazeutische Verfahrenstechnik e.V, 2016. 98: p. 76-89.

21. Varum, F.J.O., et al., Mucoadhesive platforms for targeted delivery to the colon. International Journal of Pharmaceutics, 2011. 420: p. 11-19.

22. Ugwoke, M., et al., Nasal mucoadhesive drug delivery: Background, applications, trends and future perspectives. Advanced Drug Delivery Reviews, 2005. 57(11): p. 1640-1665.

23. Maisel, K., et al., Effect of surface chemistry on nanoparticle interaction with gastrointestinal mucus and distribution in the gastrointestinal tract following oral and rectal administration in the mouse. Journal of Controlled Release, 2015. 197: p. 48-57.

24. Knoblaugh, S., J. Randolph-Habecker, and S. Rath, 3 - Necropsy and Histology A2 Treuting, Piper M, in Comparative Anatomy and Histology, S.M. Dintzis, Editor. 2012, Academic Press: San Diego. p. 15-40.

25. Washington, N., C. Washington, and C. Wilson, Physiological Pharmaceutics: Barriers to Drug Absorption. 2002: CRC Press.

26. Vareille, M., et al., The airway epithelium: soldier in the fight against respiratory viruses. Clinical microbiology reviews, 2011. 24(1): p. 210-29.

27. Birchenough, G.M.H., et al., New developments in goblet cell mucus secretion and function. Mucosal Immunology, 2015. 8: p. 712-719.

28. Macao, B., et al., Autoproteolysis coupled to protein folding in the SEA domain of the membrane-bound MUC1 mucin. Nat Struct Mol Biol, 2006. 13(1): p. 71-76.

29. Johansson, M.E.V., Fast renewal of the distal colonic mucus layers by the surface goblet cells as measured by in vivo labeling of mucin glycoproteins. PloS one, 2012. 7(7): p. e41009-e41009.

30. Meyer, F.A. and A. Silberberg, Structure and Function of Mucus. 2008, John Wiley \& Sons, Ltd. p. 203-218.

31. Boegh, M. and H.M. Nielsen, Mucus as a Barrier to Drug Delivery - Understanding and Mimicking the Barrier Properties. Basic \& Clinical Pharmacology \& Toxicology, 2014: p. n/a-n/a.

32. Sheehan, J.K., et al., The Structure and Heterogeneity of Respiratory Mucus Glycoproteins. American Review of Respiratory Disease, 1991. 144(3_pt_2): p. S4S9.

33. Davis, C.W. and B. Dickey, F., Regulated Airway Goblet Cell Mucin Secretion. Annual Review of Physiology, 2008. 70(1): p. 487-512.

34. Johansson, M.E., H. Sjovall, and G.C. Hansson, The gastrointestinal mucus system in health and disease. Nat Rev Gastroenterol Hepatol, 2013. 10(6): p. 352-61.

35. Long, J.D. and R.C. Orlando, Esophageal submucosal glands: structure and function. Am J Gastroenterol, 1999. 94(10): p. 2818-2824.

36. Shimizu, T., Mucus, Goblet Cell, Submucosal Gland in Nasal Physiology and Pathophysiology of Nasal Disorders, T.M. Önerci, Editor. 2013, Springer-Verlag Berlin Heidelberg: Berlin Heidelberg. p. 1-14.

37. Lillehoj, E.P., et al., Cellular and Molecular Biology of Airway Mucins. 2013. p. 139202.

38. Audie, J.P., et al., Mucin gene expression in the human endocervix. Human reproduction (Oxford, England), 1995. 10(1): p. 98-102.

39. Mantelli, F. and P. Argüeso, Functions of ocular surface mucins in health and disease. Current Opinion in Allergy and Clinical Immunology, 2008. 8(5): p. 477483. 
40. Netsomboon, K. and A. Bernkop-Schnürch, Mucoadhesive vs. mucopenetrating particulate drug delivery. European Journal of Pharmaceutics and Biopharmaceutics, 2016. 98: p. 76-89.

41. Johansson, M.E.V., K.A. Thomsson, and G.C. Hansson, Proteomic Analyses of the Two Mucus Layers of the Colon Barrier Reveal That Their Main Component, the Muc2 Mucin, Is Strongly Bound to the Fcgbp Protein. Journal of Proteome Research, 2009. 8(7): p. 3549-3557.

42. Taupin, D. and D.K. Podolsky, Trefoil factors: initiators of mucosal healing. Nature Reviews Molecular Cell Biology, 2003. 4(9): p. 721-732.

43. Ridley, C., et al., Assembly of the Respiratory Mucin MUC5B: A NEW MODEL FOR A GEL-FORMING MUCIN. Journal of Biological Chemistry, 2014. 289(23): p. 16409-16420.

44. Ambort, D., et al., Calcium and pH-dependent packing and release of the gel-forming MUC2 mucin. Proceedings of the National Academy of Sciences, 2012. 109(15): p. 5645-5650.

45. Ehre, C., C. Ridley, and D.J. Thornton, Cystic fibrosis: An inherited disease affecting mucin-producing organs. The International Journal of Biochemistry \& Cell Biology, 2014. 52: p. 136-145.

46. Birchenough, G.M.H., et al., New developments in goblet cell mucus secretion and function. Mucosal Immunology, 2015. 8(4): p. 712-719.

47. Gum, J.R., et al., Molecular cloning of human intestinal mucin (MUC2) cDNA. Identification of the amino terminus and overall sequence similarity to prepro-von Willebrand factor. The Journal of biological chemistry, 1994. 269(4): p. 2440-6.

48. Specian, R.D. and M.R. Neutra, Mechanism of rapid mucus secretion in goblet cells stimulated by acetylcholine. The Journal of cell biology, 1980. 85(3): p. 626-40.

49. Verdugo, P., Goblet Cells Secretion and Mucogenesis. Annual Review of Physiology, 1990. 52(1): p. 157-176.

50. Schutte, A., et al., Microbial-induced meprin cleavage in MUC2 mucin and a functional CFTR channel are required to release anchored small intestinal mucus. Proceedings of the National Academy of Sciences, 2014. 111(34): p. 12396-12401.

51. Johansson, M.E. and G.C. Hansson, Immunological aspects of intestinal mucus and mucins. Nat Rev Immunol, 2016. 16(10): p. 639-49.

52. Murty, V.L., et al., Effect of lipids and proteins on the viscosity of gastric mucus glycoprotein. Biochemical and biophysical research communications, 1984. 121(2): p. 521-9.

53. Slomiany, B.L., et al., Effect of covalently bound fatty acids and associated lipids on the viscosity of gastric mucus glycoprotein in cystic fibrosis. Digestion, 1986. 34(4): p. $275-80$.

54. Taylor, C., et al., Two rheologically different gastric mucus secretions with different putative functions. Biochimica et Biophysica Acta (BBA) - General Subjects, 2004. 1674(2): p. 131-138.

55. Zahm, J.M., et al., Comparative rheological profile of rat gastric and duodenal gel mucus. Biorheology, 1989. 26(4): p. 813-22.

56. Bustamante-Marin, X.M. and L.E. Ostrowski, Cilia and Mucociliary Clearance. Cold Spring Harbor perspectives in biology, 2016: p. a028241-a028241.

57. Nakano, F.Y., R.d.B.F. Leão, and S.C. Esteves, Insights into the role of cervical mucus and vaginal $\mathrm{pH}$ in unexplained infertility. MedicalExpress, 2015. 2(2): p. 1-8.

58. Wira, C.R., M. Rodriguez-Garcia, and M.V. Patel, The role of sex hormones in immune protection of the female reproductive tract. Nat Rev Immunol, 2015. 15(4): p. 217-230. 
59. Johansson, M.E.V., H. Sjövall, and G.C. Hansson, The gastrointestinal mucus system in health and disease. Nature Reviews Gastroenterology \& Hepatology, 2013. 10(6): p. 352-361.

60. Nicolazzo, J.A., B.L. Reed, and B.C. Finnin, Buccal penetration enhancers-How do they really work? Journal of Controlled Release, 2005. 105(1-2): p. 1-15.

61. Campisi, G., et al., Human buccal mucosa as an innovative site of drug delivery. Current pharmaceutical design, 2010. 16(6): p. 641-52.

62. Bragulla, H.H. and D.G. Homberger, Structure and functions of keratin proteins in simple, stratified, keratinized and cornified epithelia. Journal of Anatomy, 2009. 214(4): p. 516-559.

63. Diaz del Consuelo, I., et al., Evaluation of pig esophageal mucosa as a permeability barrier model for buccal tissue. Journal of Pharmaceutical Sciences, 2005. 94(12): p. 2777-2788.

64. Caon, T., et al., Enhancing the Buccal Mucosal Delivery of Peptide and Protein Therapeutics. Pharmaceutical Research, 2015. 32(1): p. 1-21.

65. Collins, L.M. and C. Dawes, The surface area of the adult human mouth and thickness of the salivary film covering the teeth and oral mucosa. Journal of dental research, 1987. 66(8): p. 1300-2.

66. Teubl, B.J., et al., In-Vitro Permeability of Neutral Polystyrene Particles via Buccal Mucosa. Small, 2013. 9(3): p. 457-466.

67. Linden, S.K., et al., Mucins in the mucosal barrier to infection. Mucosal Immunology, 2008. 1: p. 183-197.

68. Gururaja, T.L., et al., Candidacidal activity prompted by N-terminus histatin-like domain of human salivary mucin (MUC7)1. Biochim Biophys Acta, 1999. 1431(1): p. 107-19.

69. Frenkel, E.S. and K. Ribbeck, Salivary Mucins Protect Surfaces from Colonization by Cariogenic Bacteria. Applied and Environmental Microbiology, 2015. 81(1): p. 332338.

70. Helander, H.F. and L. Fandriks, Surface area of the digestive tract - revisited. Scand J Gastroenterol, 2014. 49(6): p. 681-9.

71. Meyer, W., et al., Keratinization of the esophageal epithelium of domesticated mammals. Acta Histochemica, 2014. 116(1): p. 235-242.

72. Abdulnour-Nakhoul, S., et al., Characterization of Esophageal Submucosal Glands in Pig Tissue and Cultures. Digestive Diseases and Sciences, 2007. 52(11): p. 30543065.

73. Dixon, J., et al., Esophageal mucin: an adherent mucus gel barrier is absent in the normal esophagus but present in columnar-lined Barrett's esophagus. The American Journal of Gastroenterology, 2001. 96(9): p. 2575-2583.

74. Ho, S.B., et al., Expression cloning of gastric mucin complementary DNA and localization of mucin gene expression. Gastroenterology, 1995. 109(3): p. 735-747.

75. NORDMAN, H., et al., Gastric MUC5AC and MUC6 are large oligomeric mucins that differ in size, glycosylation and tissue distribution. Biochemical Journal, 2002. 364(1): p. 191-200.

76. Audie, J.-P., et al., Mucin gene expression in the human endocervix. Human Reproduction, 1995. 10(1): p. 98-102.

77. Yandrapu, H. and J. Sarosiek, Protective Factors of the Gastric and Duodenal Mucosa: An Overview. Current Gastroenterology Reports, 2015. 17(6): p. 24-24.

78. Kelly, S.M., J.R. Crampton, and J.O. Hunter, Helicobacter pylori increases gastric antral juxtamucosal pH. Digestive diseases and sciences, 1993. 38(1): p. 129-31. 
79. Suerbaum, S. and P. Michetti, Helicobacter pylori Infection. New England Journal of Medicine, 2002. 347(15): p. 1175-1186.

80. Wong, G.L.H., et al., High Incidence of Mortality and Recurrent Bleeding in Patients With Helicobacter pylori-Negative Idiopathic Bleeding Ulcers. Gastroenterology, 2009. 137: p. 525-531.

81. Niv, Y. and D. Boltin, Secreted and Membrane-Bound Mucins and Idiopathic Peptic Ulcer Disease. Digestion, 2012. 86(3): p. 258-263.

82. Ishihara, K., et al., Effect on gastric mucus of the proton pump inhibitor leminoprazole and its cytoprotective action against ethanol-induced gastric injury in rats. Arzneimittelforschung, 1994. 44(7): p. 827-830.

83. Skoczylas, T., et al., Significant Enhancement of Gastric Mucin Content After Rabeprazole Administration: Its Potential Clinical Significance in Acid-Related Disorders. Digestive Diseases and Sciences, 2003. 48(2): p. 322-328.

84. Pelaseyed, T., et al., The mucus and mucins of the goblet cells and enterocytes provide the first defense line of the gastrointestinal tract and interact with the immune system. Immunological Reviews, 2014. 260(1): p. 8-20.

85. Resta-Lenert, S., et al., Muc17 protects intestinal epithelial cells from enteroinvasive E. coli infection by promoting epithelial barrier integrity. American Journal of Physiology - Gastrointestinal and Liver Physiology, 2011. 300(6): p. G1144-G1155.

86. Gustafsson, J.K., et al., Bicarbonate and functional CFTR channel are required for proper mucin secretion and link cystic fibrosis with its mucus phenotype. The Journal of experimental medicine, 2012. 209(7): p. 1263-72.

87. Johansson, M.E.V. and G.C. Hansson, Keeping Bacteria at a Distance. Science, 2011. 334(6053): p. 182-183.

88. Ouellette, A.J., Paneth cells and innate mucosal immunity. Current Opinion in Gastroenterology, 2010. 26(6): p. 547-553.

89. Ermund, A., et al., Gastrointestinal mucus layers have different properties depending on location - 1. Studies of mucus in mouse stomach, small intestine, Peyer's patches and colon. American Journal of Physiology - Gastrointestinal and Liver Physiology, 2013.

90. McConnell, E.L., H.M. Fadda, and A.W. Basit, Gut instincts: Explorations in intestinal physiology and drug delivery. International Journal of Pharmaceutics, 2008. 364(2): p. 213-226.

91. Johansson, M.E.V., et al., Bacteria Penetrate the Inner Mucus Layer before Inflammation in the Dextran Sulfate Colitis Model. PLOS ONE, 2010. 5(8): p. e12238.

92. Laroui, H., et al., Dextran Sodium Sulfate (DSS) Induces Colitis in Mice by Forming Nano-Lipocomplexes with Medium-Chain-Length Fatty Acids in the Colon. PLOS ONE, 2012. 7(3): p. e32084.

93. Corfield, A.P., et al., Mucin degradation in the human colon: production of sialidase, sialate $O$-acetylesterase, $N$-acetylneuraminate lyase, arylesterase, and glycosulfatase activities by strains of fecal bacteria. Infection and Immunity, 1992. 60(10): p. 39713978.

94. Rubinstein, A. and B. Tirosh, Mucus Gel Thickness and Turnover in the Gastrointestinal Tract of the Rat: Response to Cholinergic Stimulus and Implication for Mucoadhesion. Pharmaceutical Research, 1994. 11(6): p. 794-799.

95. Atuma, C., et al., The adherent gastrointestinal mucus gel layer: thickness and physical state in vivo. American journal of physiology. Gastrointestinal and liver physiology, 2001. 280(5): p. G922-9. 
96. Varum, F.J.O., et al., Mucus thickness in the gastrointestinal tract of laboratory animals. Journal of Pharmacy and Pharmacology, 2012. 64(2): p. 218-227.

97. Jordan, N., et al., A novel method for the visualization of the in situ mucus layer in rat and man. Clinical science (London, England : 1979), 1998. 95(1): p. 97-106.

98. Freire, A.C., et al., Does sex matter? The influence of gender on gastrointestinal physiology and drug delivery. International Journal of Pharmaceutics, 2011. 415(1-2): p. 15-28.

99. Hatton, G.B., et al., Animal Farm: Considerations in Animal Gastrointestinal Physiology and Relevance to Drug Delivery in Humans. Journal of Pharmaceutical Sciences, 2015. 104(9): p. 2747-2776.

100. Nugent, S.G., et al., Intestinal luminal pH in inflammatory bowel disease: possible determinants and implications for therapy with aminosalicylates and other drugs. Gut, 2001. 48(4): p. 571-7.

101. Dawson, M., et al., Transport of Polymeric Nanoparticle Gene Carriers in Gastric Mucus. Biotechnology Progress, 2004. 20(3): p. 851-857.

102. Younan, F., et al., Changes in the Structure of the Mucous Gel on the Mucosal Surface of the Stomach in Association with Peptic Ulcer Disease. Gastroenterology. 82(5): p. 827-831.

103. Markesich, D.C., et al., Helicobacter pylori infection does not reduce the viscosity of human gastric mucus gel. Gut, 1995. 36(3): p. 327-9.

104. Van Dijk, W. and A. Mackiewicz, Interleukin-6-type cytokine-induced changes in acute phase protein glycosylation. Ann N Y Acad Sci, 1995. 762: p. 319-30.

105. Dewald, J.H., et al., Role of Cytokine-Induced Glycosylation Changes in Regulating Cell Interactions and Cell Signaling in Inflammatory Diseases and Cancer. Cells, 2016. 5(4).

106. Neurath, M.F., Cytokines in inflammatory bowel disease. Nat Rev Immunol, 2014. 14(5): p. 329-42.

107. Pullan, R.D., et al., Thickness of adherent mucus gel on colonic mucosa in humans and its relevance to colitis. Gut, 1994. 35(3): p. 353-9.

108. Dorofeyev, A.E., et al., Mucosal barrier in ulcerative colitis and Crohn's disease. Gastroenterol Res Pract, 2013. 2013: p. 431231.

109. Habib, N.A., et al., A study of histochemical changes in mucus from patients with ulcerative colitis, Crohn's disease, and diverticular disease of the colon. Diseases of the Colon \& Rectum, 1986. 29(1): p. 15-17.

110. Delmotte, P., et al., Tumor necrosis factor alpha increases the expression of glycosyltransferases and sulfotransferases responsible for the biosynthesis of sialylated and/or sulfated Lewis $x$ epitopes in the human bronchial mucosa. J Biol Chem, 2002. 277(1): p. 424-31.

111. Larsson, J.M., et al., Altered O-glycosylation profile of MUC2 mucin occurs in active ulcerative colitis and is associated with increased inflammation. Inflamm Bowel Dis, 2011. 17(11): p. 2299-307.

112. Fu, J., et al., Loss of intestinal core 1-derived O-glycans causes spontaneous colitis in mice. J Clin Invest, 2011. 121(4): p. 1657-66.

113. Bergstrom, K., et al., Core 1-and 3-derived O-glycans collectively maintain the colonic mucus barrier and protect against spontaneous colitis in mice. Mucosal Immunol, 2017. 10(1): p. 91-103.

114. Yadav, V., et al., Inflammatory bowel disease: exploring gut pathophysiology for novel therapeutic targets. Translational Research, 2016. 176: p. 38-68.

115. Johansson, M.E.V. and G.C. Hansson, Immunological aspects of intestinal mucus and mucins. Nature Reviews Immunology, 2016. 16(10): p. 639-649. 
116. O'Sullivan, B.P. and S.D. Freedman, Cystic fibrosis. The Lancet. 373(9678): p. 18911904.

117. Sousa, T., et al., The gastrointestinal microbiota as a site for the biotransformation of drugs. Int J Pharm, 2008. 363(1-2): p. 1-25.

118. Varum, F.J., G.B. Hatton, and A.W. Basit, Food, physiology and drug delivery. Int J Pharm, 2013. 457(2): p. 446-60.

119. Slomiany, B.L., et al., Glycosulfatase activity of H. pylori toward human gastric mucin: effect of sucralfate. Am J Gastroenterol, 1992. 87(9): p. 1132-7.

120. Hoskins, L.C., et al., Mucin Glycoprotein Degradation by Mucin Oligosaccharidedegrading Strains of Human Faecal Bacteria. Characterisation of Saccharide Cleavage Products and their Potential Role in Nutritional Support of Larger Faecal Bacterial Populations. Microbial Ecology in Health and Disease, 1992. 5(4): p. 193207.

121. Turroni, F., et al., Genome analysis of Bifidobacterium bifidum PRL2010 reveals metabolic pathways for host-derived glycan foraging. Proc Natl Acad Sci U S A, 2010. 107(45): p. 19514-9.

122. Everard, A., et al., Cross-talk between Akkermansia muciniphila and intestinal epithelium controls diet-induced obesity. Proceedings of the National Academy of Sciences, 2013. 110(22): p. 9066-9071.

123. Derrien, M., et al., Akkermansia muciniphila gen. nov., sp. nov., a human intestinal mucin-degrading bacterium. Int J Syst Evol Microbiol, 2004. 54(Pt 5): p. 1469-76.

124. Karlsson, C.L., et al., The microbiota of the gut in preschool children with normal and excessive body weight. Obesity (Silver Spring), 2012. 20(11): p. 2257-61.

125. Everard, A., et al., Responses of gut microbiota and glucose and lipid metabolism to prebiotics in genetic obese and diet-induced leptin-resistant mice. Diabetes, 2011. 60(11): p. 2775-86.

126. Kleessen, B., L. Hartmann, and M. Blaut, Fructans in the diet cause alterations of intestinal mucosal architecture, released mucins and mucosa-associated bifidobacteria in gnotobiotic rats. Br J Nutr, 2003. 89(5): p. 597-606.

127. Desai, M.S., et al., A Dietary Fiber-Deprived Gut Microbiota Degrades the Colonic Mucus Barrier and Enhances Pathogen Susceptibility. Cell, 2016. 167(5): p. 13391353.e21.

128. Desai, M.A., M. Mutlu, and P. Vadgama, A study of macromolecular diffusion through native porcine mucus. Experientia, 1992. 48(1): p. 22-6.

129. Li, L.D., et al., Spatial configuration and composition of charge modulates transport into a mucin hydrogel barrier. Biophys J, 2013. 105(6): p. 1357-65.

130. Larhed, A.W., et al., Diffusion of drugs in native and purified gastrointestinal mucus. Journal of pharmaceutical sciences, 1997. 86: p. 660-5.

131. Beule, A.G., Physiology and pathophysiology of respiratory mucosa of the nose and the paranasal sinuses. GMS current topics in otorhinolaryngology, head and neck surgery, 2010. 9: p. Doc07-Doc07.

132. Copyright A2 - Treuting, Piper M, in Comparative Anatomy and Histology, S.M. Dintzis, Editor. 2012, Academic Press: San Diego. p. iv.

133. Tos, M., Distribution of mucus producing elements in the respiratory tract. Differences between upper and lower airway. European journal of respiratory diseases. Supplement, 1983. 128 (Pt 1): p. 269-79.

134. Petruson, B., Secretion from gland and goblet cells in infected sinuses. Acta otolaryngologica. Supplementum, 1994. 515: p. 33-6; discussion 36-7.

135. Arora, P., S. Sharma, and S. Garg, Permeability issues in nasal drug delivery. Drug Discovery Today, 2002. 7(18): p. 967-975. 
136. Majima, Y., S. Masuda, and Y. Sakakura, Quantitative study of nasal secretory cells in normal subjects and patients with chronic sinusitis. The Laryngoscope, 1997.

107(11 Pt 1): p. 1515-8.

137. Williams, O.W., et al., Airway Mucus. American Journal of Respiratory Cell and Molecular Biology, 2006. 34(5): p. 527-536.

138. Curran, D.R. and L. Cohn, Advances in Mucous Cell Metaplasia: a plug for mucus as a therapeutic focus in chronic airway disease. American Journal of Respiratory Cell and Molecular Biology, 2010. 42(3): p. 268-275.

139. Nadziejko, C. and I. Finkelstein, Inhibition of neutrophil elastase by mucus glycoprotein. American Journal of Respiratory Cell and Molecular Biology, 1994. 11(1): p. 103-107.

140. Fröhlich, E., et al., Measurements of Deposition, Lung Surface Area and Lung Fluid for Simulation of Inhaled Compounds. Frontiers in Pharmacology, 2016. 7: p. 181181.

141. Creuwels, L.A., L.M. van Golde, and H.P. Haagsman, The pulmonary surfactant system: biochemical and clinical aspects. Lung, 1997. 175(1): p. 1-39.

142. Scheithauer, M.O., Surgery of the turbinates and "empty nose" syndrome GMS Current Topics in Otorhinolaryngology - Head and Neck Surgery, 2010. 9: p. 1-28.

143. Dahl and Mygind, Anatomy, physiology and function of the nasal cavities in health and disease. Advanced drug delivery reviews, 1998. 29(1-2): p. 3-12.

144. Ali, M.S. and J.P. Pearson, Upper Airway Mucin Gene Expression: A Review. The Laryngoscope, 2007. 117(5): p. 932-938.

145. Stanley, P.J., et al., Effect of cigarette smoking on nasal mucociliary clearance and ciliary beat frequency. Thorax, 1986. 41(7): p. 519-523.

146. Hattori, M., et al., Effects of nasal allergen challenge on dynamic viscoelasticity of nasal mucus. The Annals of otology, rhinology, and laryngology, 1993. 102(4 Pt 1): p. 314-7.

147. Rubin, B.K., et al., Effect of clarithromycin on nasal mucus properties in healthy subjects and in patients with purulent rhinitis. American journal of respiratory and critical care medicine, 1997. 155(6): p. 2018-23.

148. Shin, S.-H. and W.-W. Heo, Effects of unilateral naris closure on the nasal and maxillary sinus mucosa in rabbit. Auris Nasus Larynx, 2005. 32(2): p. 139-143.

149. Majima, Y., et al., The effect of an orally administered proteolytic enzyme on the elasticity and viscosity of nasal mucus. Archives of Oto-Rhino-Laryngology, 1988. 244(6): p. 355-359.

150. Majima, Y., et al., Effect of Biochemical Components on Rheologic Properties of Nasal Mucus in Chronic Sinusitis. American Journal of Respiratory and Critical Care Medicine, 1999. 160(2): p. 421-426.

151. Song, K.S., et al., Interleukin-1 beta and tumor necrosis factor-alpha induce MUC5AC overexpression through a mechanism involving ERK/p38 mitogen-activated protein kinases-MSK1-CREB activation in human airway epithelial cells. J Biol Chem, 2003. 278(26): p. 23243-50.

152. Beum, P.V., et al., Mucin biosynthesis: upregulation of core 2 beta 1,6 Nacetylglucosaminyltransferase by retinoic acid and Th2 cytokines in a human airway epithelial cell line. Am J Physiol Lung Cell Mol Physiol, 2005. 288(1): p. L116-24.

153. Voynow, J.A. and B.K. Rubin, Mucins, mucus, and sputum. Chest, 2009. 135(2): p. 505-12.

154. Voynow, J.A., D.M. Selby, and M.C. Rose, Mucin gene expression (MUC1, MUC2, and MUC5/5AC) in nasal epithelial cells of cystic fibrosis, allergic rhinitis, and normal individuals. Lung, 1998. 176(5): p. 345-54. 
155. Audie, J.P., et al., Expression of human mucin genes in respiratory, digestive, and reproductive tracts ascertained by in situ hybridization. The journal of histochemistry and cytochemistry : official journal of the Histochemistry Society, 1993. 41(10): p. 1479-85.

156. Mathiowitz, E., D.E. Chickering, and C.-M. Lehr, Bioadhesive drug delivery systems : fundamentals, novel approaches, and development. 1999: Informa healthcare. 670670.

157. Costantino, H.R., et al., Intranasal delivery: physicochemical and therapeutic aspects. Int J Pharm, 2007. 337(1-2): p. 1-24.

158. Pires, A., et al., Intranasal drug delivery: how, why and what for? J Pharm Pharm Sci, 2009. 12(3): p. 288-311.

159. Ugwoke, M.I., N. Verbeke, and R. Kinget, The biopharmaceutical aspects of nasal mucoadhesive drug delivery. The Journal of pharmacy and pharmacology, 2001. 53(1): p. 3-21.

160. Rubin, B.K., Physiology of airway mucus clearance. Respiratory care, 2002. 47(7): p. 761-8.

161. Steimer, A., E. Haltner, and C.M. Lehr, Cell Culture Models of the Respiratory Tract Relevant to Pulmonary Drug Delivery. Journal of Aerosol Medicine, 2005. 18(2): p. 137-182.

162. Marriott, C., Mucus and mucociliary clearance in the respiratory tract. Advanced Drug Delivery Reviews, 1990. 5(1-2): p. 19-35.

163. Sleigh, M.A., J.R. Blake, and N. Liron, The propulsion of mucus by cilia. Am Rev Respir Dis, 1988. 137(3): p. 726-41.

164. Duncan, G.A., et al., The Mucus Barrier to Inhaled Gene Therapy. Mol Ther, 2016. 24(12): p. 2043-2053.

165. Zhu, Y., A. Chidekel, and T.H. Shaffer, Cultured Human Airway Epithelial Cells (Calu-3): A Model of Human Respiratory Function, Structure, and Inflammatory Responses. Critical Care Research and Practice, 2010. 2010: p. 1-8.

166. Rose, M.C. and J.A. Voynow, Respiratory Tract Mucin Genes and Mucin Glycoproteins in Health and Disease. Physiological Reviews, 2006. 86(1): p. 245278.

167. Kirch, J., et al., Optical tweezers reveal relationship between microstructure and nanoparticle penetration of pulmonary mucus. Proceedings of the National Academy of Sciences of the United States of America, 2012. 109(45): p. 18355-60.

168. Randell, S.H. and R.C. Boucher, Effective mucus clearance is essential for respiratory health. American journal of respiratory cell and molecular biology, 2006. 35(1): p. 20-8.

169. Nadel, J.A., Mucous hypersecretion and relationship to cough. Pulmonary Pharmacology \& Therapeutics, 2013. 26(5): p. 510-513.

170. Horsley, A., et al., Reassessment of the importance of mucins in determining sputum properties in cystic fibrosis. Journal of Cystic Fibrosis, 2014. 13(3): p. 260-266.

171. Burgel, P.R., et al., A morphometric study of mucins and small airway plugging in cystic fibrosis. Thorax, 2007. 62(2): p. 153-161.

172. Groneberg, D.A., et al., Expression of MUC5AC and MUC5B mucins in normal and cystic fibrosis lung. Respiratory Medicine, 2002. 96(2): p. 81-86.

173. Khan, T.Z., et al., Early pulmonary inflammation in infants with cystic fibrosis. Am J Respir Crit Care Med, 1995. 151(4): p. 1075-82.

174. Bonfield, T.L., et al., Inflammatory cytokines in cystic fibrosis lungs. Am J Respir Crit Care Med, 1995. 152(6 Pt 1): p. 2111-8. 
175. Bonfield, T.L., M.W. Konstan, and M. Berger, Altered respiratory epithelial cell cytokine production in cystic fibrosis. J Allergy Clin Immunol, 1999. 104(1): p. 72-8.

176. Weber, A.J., et al., Activation of NF-kappaB in airway epithelial cells is dependent on CFTR trafficking and Cl- channel function. Am J Physiol Lung Cell Mol Physiol, 2001. 281(1): p. L71-8.

177. Lamblin, G., et al., Human airway mucin glycosylation: a combinatory of carbohydrate determinants which vary in cystic fibrosis. Glycoconj J, 2001. 18(9): p. 661-84.

178. Groux-Degroote, S., et al., IL-6 and IL-8 increase the expression of glycosyltransferases and sulfotransferases involved in the biosynthesis of sialylated and/or sulfated Lewisx epitopes in the human bronchial mucosa. Biochem J, 2008. 410(1): p. 213-23.

179. Andersch-Björkman, Y., et al., Large Scale Identification of Proteins, Mucins, and Their O-Glycosylation in the Endocervical Mucus during the Menstrual Cycle. Molecular \& Cellular Proteomics, 2007. 6(4): p. 708-716.

180. Chantler, E.N. and P.R. Scudder, Terminal glycosylation in humna cervical mucin, in Mucus and Mucosa, C.F.S. 109, Editor. 1984, Pitman Publishing Ltd: New Jersey. p. 180-188.

181. Moghissi, K.S., Cervical factor in infertility, in Reproductive medicine and Surgery, E.E. Wallach and A.A. Zacur, Editors. 1995, Mosby Book Co: Chicago, USA. p. 376397.

182. Shukair, S.A., et al., Human cervicovaginal mucus contains an activity that hinders HIV-1 movement. Mucosal Immunol, 2013. 6(2): p. 427-434.

183. HUGGINS, G.R. and G. PRETI, VAGINAL ODORS AND SECRETIONS. Clinical Obstetrics and Gynecology, 1981. 24(2): p. 355-377.

184. Owen, D.H., et al., Biophysical Analysis of Prototype Microbicidal Gels. Journal of Pharmaceutical Sciences, 2006. 96(3): p. 661-669.

185. Kieweg, S.L. and D.F. Katz, Squeezing Flows of Vaginal Gel Formulations Relevant to Microbicide Drug Delivery. Journal of Biomechanical Engineering, 2006. 128(4): p. $540-553$.

186. Moriyama, A., et al., Secretory leukocyte protease inhibitor (SLPI) concentrations in cervical mucus of women with normal menstrual cycle. MHR: Basic science of reproductive medicine, 1999. 5(7): p. 656-661.

187. Gipson, I.K., et al., The Amount of MUC5B Mucin in Cervical Mucus Peaks at Midcycle1. The Journal of Clinical Endocrinology \& Metabolism, 2001. 86(2): p. 594-600.

188. Gilks, C.B., et al., Histochemical changes in cervical mucus-secreting epithelium during the normal menstrual cycle. Fertility and Sterility, 1989. 51(2): p. 286-291.

189. Van Kooij, R.J., et al., Human Cervical Mucus and its Mucous Glycoprotein during the Menstrual Cycle*. Fertility and Sterility, 1980. 34(3): p. 226-233.

190. Katz, D.F., E.Z. Drobnis, and J.W. Overstreet, Factors regulating mammalian sperm migration through the female reproductive tract and oocyte vestments. Gamete Research, 1989. 22(4): p. 443-469.

191. Florence, A.T. and D. Attwood, Physicochemical Principles of Pharmacy 5th ed. 2011, London: Pharmaceutical Press.

192. Macklaim, J.M., et al., At the crossroads of vaginal health and disease, the genome sequence of Lactobacillus iners AB-1. Proceedings of the National Academy of Sciences, 2011. 108(Supplement 1): p. 4688-4695. 
193. O'Hanlon, D.E., T.R. Moench, and R.A. Cone, Vaginal pH and Microbicidal Lactic Acid When Lactobacilli Dominate the Microbiota. PLOS ONE, 2013. 8(11): p. e80074.

194. Ravel, J., et al., Vaginal microbiome of reproductive-age women. Proceedings of the National Academy of Sciences, 2011. 108(Supplement 1): p. 4680-4687.

195. Nunn, K.L., et al., Enhanced Trapping of HIV-1 by Human Cervicovaginal Mucus Is Associated with Lactobacillus crispatus-Dominant Microbiota. mBio, 2015. 6(5).

196. Domino, S.E., et al., Cervical mucins carry $\alpha(1,2)$ fucosylated glycans that partly protect from experimental vaginal candidiasis. Glycoconjugate Journal, 2009. 26(9): p. $1125-1134$.

197. Saltzman, W.M., et al., Antibody diffusion in human cervical mucus. Biophys J, 1994. 66(2 Pt 1): p. 508-15.

198. Tacket, C.O., et al., Protection by Milk Immunoglobulin Concentrate against Oral Challenge with Enterotoxigenic Escherichia coli. New England Journal of Medicine, 1988. 318(19): p. 1240-1243.

199. Fahrbach, K.M., et al., Differential binding of $\operatorname{Ig} G$ and $\operatorname{IgA}$ to mucus of the female reproductive tract. PLoS One, 2013. 8(10): p. e76176.

200. Kobayashi, K., et al., Distribution and partial characterisation of Ig G Fc binding protein in various mucin producing cells and body fluids. Gut, 2002. 51(2): p. 169-76.

201. Harada, N., et al., Human IgGFc Binding Protein (Fc $\gamma B P$ ) in Colonic Epithelial Cells Exhibits Mucin-like Structure. Journal of Biological Chemistry, 1997. 272(24): p. 15232-15241.

202. Wada, A. and H. Nakamura, Nature of the charge distribution in proteins. Nature, 1981. 293(5835): p. 757-758.

203. Lai, S.K., et al., Rapid transport of large polymeric nanoparticles in fresh undiluted human mucus. Proc Natl Acad Sci U S A, 2007. 104(5): p. 1482-7.

204. Ensign, L.M., et al., Mucus penetrating nanoparticles: biophysical tool and method of drug and gene delivery. Adv Mater, 2012. 24(28): p. 3887-94.

205. Maisel, K., et al., Nanoparticles coated with high molecular weight PEG penetrate mucus and provide uniform vaginal and colorectal distribution in vivo.

Nanomedicine, 2016. 11(11): p. 1337-1343.

206. Ensign, L.M., et al., Enhanced vaginal drug delivery through the use of hypotonic formulations that induce fluid uptake. Biomaterials, 2013. 34(28): p. 6922-6929.

207. Ensign, L., R. Cone, and J. Hanes, Nanoparticle formulations with enhanced mucosal penetration. 2016, The Johns Hopkins University, US9415020 B2.

208. Henry, C.E., et al., Anti-PEG antibodies alter the mobility and biodistribution of densely PEGylated nanoparticles in mucus. Acta Biomaterialia, 2016. 43: p. 61-70.

209. Gipson, I.K. and P. Argüeso, Role of Mucins in the Function of the Corneal and Conjunctival Epithelia, in International Review of Cytology. 2003, Academic Press. p. 1-49.

210. Argüeso, P. and I.K. Gipson, Epithelial Mucins of the Ocular Surface: Structure, Biosynthesis and Function. Experimental Eye Research, 2001. 73(3): p. 281-289.

211. Woodward, A.M. and P. Argüeso, Expression Analysis of the Transmembrane Mucin MUC20 in Human Corneal and Conjunctival EpitheliaMUC20 Expression at the Ocular Surface. Investigative Ophthalmology \& Visual Science, 2014. 55(10): p. 6132-6138.

212. Hanna, C., Proliferation and Migration of Epithelial Cells*. American Journal of Ophthalmology, 1966. 61(1): p. 55-63.

213. Gipson, I.K., Distribution of mucins at the ocular surface. Experimental Eye Research, 2004. 78(3): p. 379-388. 
214. Gipson, I.K., Goblet cells of the conjunctiva: A review of recent findings. Progress in Retinal and Eye Research, 2016. 54: p. 49-63.

215. Gipson, I.K. and A.S. Tisdale, Visualization of Conjunctival Goblet Cell Actin Cytoskeleton and Mucin Content in Tissue Whole Mounts. Experimental Eye Research, 1997. 65(3): p. 407-415.

216. Jumblatt, M.M., et al., MUC7 Expression in the Human Lacrimal Gland and Conjunctiva. Cornea, 2003. 22(1): p. 41-45.

217. Gipson, I.K., Distribution of mucins at the ocular surface. Exp Eye Res, 2004. 78(3): p. 379-88.

218. McKenzie, R.W., J.E. Jumblatt, and M.M. Jumblatt, Quantification of MUC2 and MUC5AC Transcripts in Human Conjunctiva. Investigative Ophthalmology \& Visual Science, 2000. 41(3): p. 703-708.

219. Jumblatt, M.M., R.W. McKenzie, and J.E. Jumblatt, MUC5AC mucin is a component of the human precorneal tear film. Investigative Ophthalmology \& Visual Science, 1999. 40(1): p. 43-49.

220. Paulsen, F., et al., Human lacrimal gland mucins. Cell and Tissue Research, 2004. 316(2): p. 167-177.

221. Prydal, J.I. and F.W. Campbell, Study of precorneal tear film thickness and structure by interferometry and confocal microscopy. Investigative Ophthalmology \& Visual Science, 1992. 33(6): p. 1996-2005.

222. Dogru, M., et al., Alterations of the ocular surface epithelial MUC16 and goblet cell MUC5AC in patients with atopic keratoconjunctivitis. Allergy, 2008. 63(10): p. 13241334.

223. Dogru, M., et al., Atopic Ocular Surface Disease: Implications on Tear Function and Ocular Surface Mucins. Cornea, 2005. 24(8): p. S18-S23.

224. Kunert, K.S., et al., Alteration in Goblet Cell Numbers and Mucin Gene Expression in a Mouse Model of Allergic Conjunctivitis. Investigative Ophthalmology \& Visual Science, 2001. 42(11): p. 2483-2489.

225. Bonini, S., et al., Vernal keratoconjunctivitis. Eye, 2004. 18(4): p. 345-351.

226. Argüeso, P., et al., Decreased Levels of the Goblet Cell Mucin MUC5AC in Tears of Patients with Sjögren Syndrome. Investigative Ophthalmology \& Visual Science, 2002. 43(4): p. 1004-1011.

227. Schäfer, G., et al., Tränendrüsenassoziierte Muzine. Der Ophthalmologe, 2005. 102(2): p. 175-183.

228. Yu, D.F., et al., MUC19 expression in human ocular surface and lacrimal gland and its alteration in Sjögren syndrome patients. Experimental Eye Research, 2008. 86(2): p. 403-411.

229. Watanabe, H., Significance of Mucin on the Ocular Surface. Cornea, 2002. 21: p. S17-S22.

230. Argüeso, P., et al., The Cell-Layer- and Cell-Type-Specific Distribution of GalNAcTransferases in the Ocular Surface Epithelia Is Altered during Keratinization. Investigative Ophthalmology \& Visual Science, 2003. 44(1): p. 86-92.

231. Gause, S., et al., Mechanistic modeling of ophthalmic drug delivery to the anterior chamber by eye drops and contact lenses. Adv. Coll. Interface Sci., 2016. 233: p. 139154.

232. Ribeiro, A.M., A. Figueiras, and F. Veiga, Improvements in Topical Ocular Drug Delivery Systems: Hydrogels and Contact Lenses. J. Pharm. Pharm. Sci., 2015. 18(5): p. 683-695.

233. Davies, N.M., Biopharmaceutical Considerations In Topical Ocular Drug Delivery. Clinical and Experimental Pharmacology and Physiology, 2000. 27(7): p. 558-562. 
234. Zhu, H. and A. Chauhan, Effect of Viscosity on Tear Drainage and Ocular Residence Time. Optometry and Vision Science, 2008. 85(8): p. E715-E725.

235. Hull, D.S., H.F. Edelhauser, and R.A. Hyndiuk, Ocular penetration of prednisolone and the hydrophilic contact lens. Archives of Ophthalmology, 1974. 92(5): p. 413416.

236. Bengani, L.C., et al., Contact lenses as a platform for ocular drug delivery. Exp. Opinion Drug Deliv., 2013. 10(11): p. 1483-1496.

237. Hori, Y., et al., Mucins and Contact Lens Wear. Cornea, 2006. 25(2): p. 176-181.

238. Schopf, L., et al., Ocular Pharmacokinetics of a Novel Loteprednol Etabonate 0.4\% Ophthalmic Formulation. Ophthalmology and Therapy, 2014. 3(1): p. 63-72.

239. Schopf, L., et al., Enhanced Topical Delivery of a Novel Loteprednol Etabonate Ophthalmic Formulation. Investigative Ophthalmology \& Visual Science, 2014. 55(13): p. 1533-1533.

240. Schopf, L.R., et al., Topical Ocular Drug Delivery to the Back of the Eye by MucusPenetrating Particles. Translational Vision Science \& Technology, 2015. 4(3): p. 1111. 


\section{FIGURE CAPTIONS}

Figure 4: Assembly of the MUC2 mucin in the goblet cell. ER, endoplasmic reticulum; TGN, trans-Golgi network. Reprinted with permission from [46].

Figure 5: The mucin-release mechanism in the small intestine. Reprinted with permission from [51].

Figure 6: The organization of epithelium and mucus in the gastrointestinal tract. Reprinted with permission from [59].

Figure 4: Model of how a fiber-deprived gut microbiota mediates degradation of the colonic mucus barrier and heightened pathogen susceptibility. Reprinted with permission from [127].

Figure 5: Cell types of the nasal epithelium showing ciliated cell (A), non-ciliated cell (B), goblet cells (C), gel mucus layer (D), sol layer (E), basal cell (F) and basement membrane (G). Reprinted with permission from [22].

Figure 6: Diagram of the anterior portion of the eye (A), stratified epithelium of the cornea (B), stratified epithelium of the conjunctiva (C), epithelia of the lacrimal gland (D). Reprinted with permission from [209].

Figure 7: Diagram of the tear film and its interface with the ocular surface epithelium. Reprinted with permission from [217]. 